\title{
71-Sosyal medya, katılımcı kültür ve kitle çevirisi
}

Nur Emine KOÇ

APA: Koç, N. E. (2020). Sosyal medya, katılımcı kültür ve kitle çevirisi. RumeliDE Dil ve Edebiyat Araşttrmaları Dergisi, (Ö8), 905-927. DOI: 10.29000/rumelide.822087.

\section{$\ddot{\mathbf{O} z}$}

Sosyal Medya günümüzde sadece bir kitle iletişim aracı olarak yaygın kullanılmakla kalmayıp, küreselleşmenin önemli bir unsuru, bir güç temsili olarak da karşımıza çıkmaktadır. Sosyal paylaşım ağlarının gücü, hem bireysel, hem kültürel hem de toplumsal etkileşimi sağlayarak; ekonomiye, siyasete, kültürel ve gündelik hayata gündem oluşturacak bir güç kaynağı olmaktadır. Enformasyonun dağılımının ve bilginin görsele dökülmesinin en kolay ve hızlı bir yaygınlaştırma aracı olarak da tanımlanabilen sosyal medya, katılımcı kültür oluşturmada kullanılan en önemli unsurlardan biridir. Katılımcı kültür, üre-tüketici (üretici-tüketici )konumundaki kullanıcıların içerik üretmede en uç noktaya ulaştı̆̆ı, kolay ve hızlı içerik üretebildiği ve tüketebildiği bir topluluktur. Önceleri boş zamanı değerlendirme olarak düşünülen sosyal medya, günümüzde özellikle pandemi döneminde hayatlarımızın odak noktasına oturmuş, zaman ve mekân kavramlarından muaf olduğundan, gündelik hayatlarımızı idame ettirmede odak noktası haline gelmiştir. Henry Jenkins'e göre sosyal medyanın en önemli özelliği yayılabilir olmasıdır. Yayılabilir olmasını sağlayan da üre-tüketicilerdir. İçeriklerin yayılmasında etkin rol alan üre-tüketiciler hem katılımcı kültürün bir parçası, hem de tüketimin birer metası haline gelmektedirler. 21. Yüzyıl, tüketim toplumu olarak da adlandırılabilir. Bu nedenle sosyal medyanın dili çok önemlidir. Kullanılan üslup, seçilen kelimeler katılımcı kültürün toplumsal ve küresel öğelerini oluşturur. Bu araştırmanın amacı Web 2.0 tabanlı sosyal medya platformlarında kullanılan evrensel dil ve kültürel kimliklerin çeviri bağlamında araştırılması, sosyal medya içeriklerinin katılımcı kültüre hizmet ve kitle çevirisinin fonksiyonelliği ve evrenselliği ve bunun tüketim toplumuna katkısının incelenmesidir. Araştırma, Twitter, Google, Facebook ve Wikipedia'da oluşturulan popüler içeriklerin analizi, buna bağlı olarak kitle çevirisi, etkisi ve sosyal medya fenomenleri örnekleriyle ve sosyal medyada kitle çevirisi kullanıcılarına tüketim kültürü bağlamındaki etkisi anket tekniği kullanılarak araştırılmıştır.

Anahtar kelimeler: Sosyal medya, katılımcı kültür, kitle çeviri, popüler kültür

\section{Social media, participatory culture and crowdsourcing translation}

\begin{abstract}
Social media is a commonly used communication tool as well as an important factor for globalization and representation of power in today's world. The power of social networks provides personal, cultural and social interaction; thus, becoming a power source that turns into a current issue for the economy, politics, cultural and daily life. Social media which can be defined as the easiest and fastest dissemination tool for the distribution and visualization of information is an important factor used to form a participatory culture. Participatory culture is a community in which
\end{abstract}

Dr. Öğr. Üyesi, İstanbul Aydın Üniversitesi, İletişim Fakültesi, Yeni Medya ve İletişim Bölümü (İstanbul, Türkiye) nurkoc@aydin.edu.tr, ORCID ID: 0000-0002-3477-8019 [Makale kaylt tarihi: 11.09.2020-kabul tarihi: 20.11.2020; DOI: $10.29000 /$ rumelide.822087] 


\begin{abstract}
users at the pro-consumer (producer-consumer) position reach the extreme point in producing content and can easily and rapidly produce and consume content. Social media which was considered as a way to spend free time has now been at the center of our lives especially during the pandemic, and has become the focal point in maintaining our daily lives as it is free from the concepts of time and space. According to Henry Jenkins, the most important feature of social media is its ability to spread. Pro-consumers enable it to spread. Pro-consumers who have an active role in spreading content become both a part of the participatory culture and a commodity of consumption. The 21st century can be named as the consumerist society. Therefore, the language used on social media is of great importance. The style used and words chosen constitute the social and global elements of the participatory culture. The objective of this study is to investigate the universal language and cultural identities used in Web 2.0 based social media platforms in the context of translation, and to analyze social media content in terms of service to popular culture and crowdsourcing translation. In this work, the analysis of popular content created on Facebook, Twitter, Google and Wikipedia, in parallel with the effects of crowdsourcing translation within the context of consumer culture effects on the users of social media and crowdsourcing translators are analyzed by survey technique.
\end{abstract}

Keywords: Social Media, participatory culture, crowdsourcing translation, popular culture.

\title{
1. Giriş
}

İnternetin ortaya çıkışı ve hızına yetişilemeyen gelişimi, alışkanlıklarımızda ve davranış şekillerimizde devrim yaratmıştır. Bir yandan da iletişim ve bilgiye erişim için büyük fırsatlar sunan yeni medya platformlarının asosyalliği tetiklediğine dair eleştiriler de azımsanmayacak kadar çoktur. Fakat özellikle pandemi süreci yaşayan dünyada, dijitalleşmeyle değişen alışkanlıklarımızın daha çok farkına vararak, dijital dünyada var olma şekillerimiz ve süreçlerimiz daha da belirgin hale gelmiştir. Bu süreçte ekran karşısında giderek daha fazla saat geçirdiğimizi fark ettik ve hatta ekran karşısına kitlendik. Eğitimden bankacılık işlemlerine, oyunlardan ürün satışlarına, para yardımlarından alışverişe, geçmişte doğrudan insan teması gerektiren pek çok iş, yeni medya aracılığıyla gerçekleştirilmeye başlanmış, dünyanın yaşam biçiminin dijitale doğru evrildiği pandemi döneminde bu durum, daha da belirgin hale gelmiştir.

Katılımcı bilgi paylaşımını, kullanıcılar arasında etkileşimi ve işbirliğini ve sosyal ağlar, bloglar ve wiki gibi kullanıcılar tarafından oluşturulan içeriklerin oluşturulmasını kolaylaştıran web uygulamaları ile Web 2.0 sayesinde yeni iletişim biçimleri ortaya çıkmıştır. Bu uygulamalar arasında kitle kaynak kullanımı büyük önem arz etmektedir. Kitle kaynak kullanımı terimi, 1990'ların sonunda "kalabalı̆̆ı" da dâhil ederek işlerin daha kolay işlemesinin yeni bir yolunu belirtmek için oluşturulmuştur. Sürekli olarak ivme kazanan ve şimdiye kadar çok çeşitli alanlara nüfuz eden kitle kaynaklı çalışma kavramı, "crowd" ve "outsourcing" kelimelerinin birleşmesi ile oluşmuştur.

Kitle kaynak kullanımının arkasındaki fikir, "çoğunluk"un güçlü olduğu ve "az" a göre daha belirleyici seçimler yaptığı ve "kalabalığın" büyük bir potansiyele sahip olduğu fikridir. Sosyal medya platformlarında, bilgi ve yetkinliklere sahip olan, ancak bunları profesyonel yaşamlarında kullanma şansı olmayan insan sayısı gitgide artmaktadır. Hem üretici, hem de tüketici pozisyonunda olan sosyal medya kullanıcıları, kitle kaynak kullanımıyla ilgi alanlarını sürdürme fırsatı yakalayarak katılımcı kültür oluştururlar. 
Katılımcı kültür, Fuchs'a göre, kullanıcılar, izleyiciler, tüketicilerin, hayran kitlesinin ve taraftarların sosyal medya platformlarında içerik oluştururken, kültür yaratmaya dâhil olmasını belirlemek için kullanılan terimdir (Fuchs, 2014: 76). İçerik üretilen alanlar günümüzde daha çok popüler kültürde ön planda olan oyunlar, diziler, sinema filmleri ve her türlü haber içeriği kaynaklıdır. Katılımcı kültür, halk kültürünün dijitalleşmiş halidir. Kullanıcıların özgür platformlarda kendilerini ifade etmeleri, yaratıcılıklarını sergilerken anında geri dönüt alabilmeleri ve gerçek hayatta ulaşabileceklerinden çok daha fazla sayıda kişiye ve çok daha kısa zamanda ulaşabilerek taraftar toplayabilmesi, bu kültürün oluşumundaki en önemli unsurlarındandır. Diğer yandan çok fazla kişiyi kısa zamanda etkileyebildiğinden sömürgeci sistemin dijitalleşmiş hali olduğu da düşünülmektedir. Buradaki en önemli çatışma aslında, kalabalığın bilgeliğinin nasıl kullanılacağı ve yönlendirileceğidir. Marx’n terimiyle "ücretsiz emeğin" kontrolsüz ve amatörce kullanımını, çalışma zamanı ile boş zaman kavramı arasındaki çizginin bulanık hale gelişi, bu yaklaşımın toplumlar üzerindeki etkisi üzerindeki endişeleri ayyuka çıkarmıştır.

Birçok alanda etkisini gördüğümüz katılımcı kültür, fotoğrafçllıtan pazarlamaya, bilimden kar amacı gütmeyen sektörlere - özellikle dijital gazetecilik ve insani yardım projelerine-sürekli değişim halinde olan çok çeşitli alanlara nüfuz etmiştir. Katılımcı kültür oluşturmada kitle kaynak kullanımının belirgin özellikleri: kısa sürede çoğunluk oluşturma, kendilerini ilgi alanlarını ve hedefleri paylaşan bir topluluk olarak gören ve ortak bir hedef doğrultusunda işbirliği içinde çalışmaya istekli olan tüm ilgili katılımcılar arasında güçlü bir bağ oluşturmaktır. Bu bağ ile birlikte hedeflenen iş çok daha kısa sürede ve çoğunluğun ücretsiz emeği ile gerçekleşerek sosyal medyada en çok ilgi gören paylaşım olarak da hem reklam sektörüne hem de çalışma hayatına katkı sağlayabilmektedir.

Henry Jenkins'e göre sosyal medyanın en önemli özelliği hızlı ve zamansız bir şekilde yayılabilir olmasıdır. Katılımcı kültürün yaratmış olduğu üreten ve tüketen üre-tüketiciler de bu kitleleri etkileyen içeriklerin hem oluşmasında hem de yayılmasında büyük etken olmaktadırlar. Birbirleriyle sürekli etkileşimde olan katılımcılar, yeni bir içeriğin yaratılmasında ve yayılmasında aktif rol alarak katılımcı kültürünü oluştururlar (Jenkins, 2008: 331).

$\mathrm{Bu}$ kültürün oluşumunda önemli bir yeri de dilin evrenselliği almaktadır. Sosyal medya platformlarında kullanılan dil, Türkçe açısından da diğer diller açısından da ele alındığında, katılımcı kültürün yarattığı bir ortak dile dönüştüğü gözlemlenmektedir. Türkçede bazı kelimelerin karşılıkları olsa da, sosyal medya platformlarının hem ortak bir dili hem de kendi platformuna özel oluşturan ayrı bir dili bulunmaktadır. Örneğin likelamak(beğenmek), stalklamak, tweetlemek gibi. Şüphesiz ki çok fazla kullanılan sosyal medya platformları, gündelik konuşma dilini her dilde etkilediği gibi Türkçeyi de etkilemekte ve daha evrensel kalıplar haline sokmaktadır.

$\mathrm{Bu}$ evrensellik kapsamında kullanılan çeviri teknolojileri aynı derecede bu kültürün oluşumunu desteklemiştir. Çeviri tekniklerinin dijitalleşme yolunda hayatı kolaylaştırması, iletişimi sağlama yolunda önemli adımlar atması, sosyal medya platformlarında içerik oluşumunu hızlandırmış ve kolaylaştırmıştır. Kolaylık, hız, zaman ve mekân sınırı olmaması sosyal medya platformlarını vazgeçilmez kılan özellikleridir. Kitle çevirisiyle bilinen çeviri stratejilerinin formatı tamamen değişime uğramıştır. Her gün yeni uygulamalarla daha da şekillenen dijital çeviri motorları, yapay zekânın kullanımı gün geçtikçe daha da etkin ve kullanılır hale gelmiştir. Kullanımı günbegün artan bu yeni medya teknolojisi, uzman çevirmenler tarafından eleştirilere de maruz kalmıştır. Kalıcı olacağı düşünülmese de emin adımlarla katılımcı kültür oluşumunun en önemli ögelerinden birisi olarak birçok yeni medya platformlarında yerini almaktadır. 
Bu çalışmada da katılımcı kültürün oluşumuna etkisi bulunan çeviri motorları incelenmiştir. Yüksek kalitede bir çeviri getirisi olmasa da, iletişimi sağlamaya yarayan bu dijital çeviriler kültürün devamlılığını sağlar olduğundan kalıcı hale gelmiş ve sosyal medyada evrenselliği sağlayan önemli yapı taşlarından biri olmuştur. Bu sebeple bu çalışmada Facebook, Twitter ve Google gibi güçlü ve katılımcı kültürün oluşumunda önemli yerleri olan sosyal medya platformlarının kullandıkları kitle çeviri formları, özellikle Türkiye baz alınarak dünyadaki, katılımcı kültürle benzerlik ve farklılıkları araştırılmıştır.

Çalışmanın ilk bölümü yeni medyaya genel bakış ve yeni medyada dilin evrenselliği tartışılmış, ikinci bölümünde ise sosyal medya ve katılımcı kültürün oluşumu ve üretüketici popüler kültürü oluşturma ve tüketime sevki yönünden ele alınmıştır. Son bölümde ise sosyal medyada kitle çevirisinin aktif kullanımı ve kullanıcı etkileşimleri, gelecekteki gelişimi, riskleri ve firsatları anket tekniği kullanılarak araştırılmıştır.

\subsection{Yeni medya ve dil:}

İnternet ile birlikte kökünden değişim yaşayan dünya, yeni medya platformları ile anında yayın yapma, enformasyon toplama mekândan ve zamandan bağımsız bir etkileşim haline girmiştir. Dizüstü bilgisayarlardan akıllı telefonlara, GPS sistemlerinden pek çok teknolojik gelişimle birlikte yeni medya da toplumu şekillendiren bir yapıya evrilmiştir. Bununla birlikte yeni topluluklar, yeni sektörler devreye girmiş, sosyal ağların gücüyle işbirlikçi çalışmalar artmış ve enformasyon yayılımı son noktaya ulaşmıştır. Dünyada internet erişimi fazlalaştıkça, yeni medya, geleneksel kitle iletişim araçlarının önüne geçerek, günden güne büyük bir hızla yükselmiş, kullanıcılarının eskisine nazaran daha zengin içeriklere daha kısa sürede ulaşmasını sağlayarak, daha hızlı, işbirlikçi ve birçok fonksiyonu kendi içinde entegre etmesiyle birlikte tüm katılımcıların vazgeçilmez odak noktası haline gelmiştir. Bu dijital etkileşimli iletişim şekli insanları, tüketim davranışlarından, popüler kültür odaklanmalarına kadar değişikliğe uğratarak en sonunda davranış ve düşünce biçimlerini, bununla birlikte dil kullanımlarını da değiştirmiştir.

Yeni medya platformları izleyiciyi, katılımcı, üretici ve tüketici olarak içerik üretimine de katkıda bulunmasını sağlayan aktif bir kullanıcı haline getirmiştir. Yeni medyada anlam üretimini sağlayan ve hem üretici hem de tüketici olarak medya metinlerine yön verebilen yeni medya kullanıcıları, aktif bir şekilde içerik üreterek yeni medyanın oluşumuna ve devamını sağladıklarından, katılımcı kültürü oluşturan bir öğe haline gelmiştir. Tüm yeni medya uygulamaları ve Web 2.0 teknolojileri sayesinde katılımcının etkileşimli hale gelişiyle birlikte "yeni sosyal" tanımı da ortaya çıkmıştır. Kullanıcı odaklı yapıyla bilgisayar ekrana kilitlenen yeni medya katılımcısı, bu platformların içinde, kendi sosyalini, kendi ahlak normlarını ve buna dayalı kendi etik kurallarını, kendi evrensel dilini dijitale göre oluşturmuş ve etkileşime yeni bir boyut kazandırarak yeni bir dijital sosyal bir yapı ve toplum oluşumu gelişmiştir.

Yeni medya platformlarında kullanılan dile bakıldığında, Umberto Eco'nun da dediği gibi dil, karşılıklı olarak etkileşim halinde olan insanların ortak bir paydada buluşması (kültür, sanat, din, vs.), sözlü sözsüz tüm sembolleri ve göstergeleri içeren ve iletişimi sağlayan bir araçtır (Eco, 2001: 70). Yeni medyada da dil, görsel ve işitsel öğelerle etkin bir şekilde kullanılmaktadır. Teknolojik gelişimler ve yeni medya ile dilin anlaşılırlığına ve ortak paydada birleşimine daha fazla ihtiyaç duyulmuştur ve bu ihtiyaç günbegün artmaktadır. Cümlelerin anlamlanması ve kaynaktan alıcıya mesajın iletilebilmesi için ortak bir paylaşımda, kodda buluşması gerekir. Anlam bütünlüğü de dil dizgesi ile gerçekleşir 
(Chomsky, 2002: 136). Dil dizgesinin kuralları iletişimin gerçekleşmesini sağlar. Dile üç farklı bakış açısı ile bakan Saussure, "Langage" ile insanların konuşma yetisini, "langue" ile soyut anlamlar yapısını "parole" ile ise de konuşma eyleminin kendisini tanımlar (Sausure,1985: 25). Birbiriyle ilişkili dizgelerin anlamlı dizilimi ile oluşan yeni medyanın dili de çoğunlukla evrensel imgeler içerir.

Evrensel dil olarak da ana akım medyada ve yeni medyada da baskın dil İngilizcedir. Hem kolay öğrenilip, kısa zamanda pratik şekilde konuşulabilirliğinden, hem de yüzylllardır süre gelen pek çok sömürge devletinin dünyada kullandığı ortak dil ve teknolojik gelişimlerin odağı olan ülkelerin kullandığı ortak dil olduğundan, etkin bir şekilde kullanılan İngilizce, yeni medyanın dilidir de denilebilir. Bunun yanında bu çalışmada da tartışıldığı gibi sosyal medyada oluşturulan katılımcı kültürün ortak dili için yapılan çalışmalar da çoğunlukla başka dillerin İngilizceye ya da İngilizceden diğer dillere yerelleştirme yapılarak aktarımı şeklindedir.

Küreselleşmenin etkisiyle ana akım medyada da görülen dilin evrenselleşme sürecinde, Türkçe de diğer diller gibi popüler kültürden etkilenmiştir. Kullanılan kelimeler daha evrensel olup özellikle İngilizce kelimelerden oluşmaktadır. Sosyal Medyanın dili Türkiye'de de yıllar içinde şekillenmiş, gündelik dilde de kullanılır hale gelmiştir. Bunun yaygınlaşma sebebi ise teknolojik gelişmeler ve internetin daha uygun fiyata ve yaygın kullanımıdır ama daha çok yeni medyanın yaygın ve yoğun kullanımından kaynaklanan dijital kültürün kullanıcılar üzerindeki etkisidir.

Cep telefonlarında da internet kullanımının ucuza mal olması, kolay ve pratik kullanımı ile sosyal medya platformları artık boş zamanlar için kullanılmaktan çıııp günlük hayatın vazgeçilmez bir parçası haline gelmiştir. Özellikle genç kuşağın yeni sosyalleşme alanı olup tüm duygusal, ekonomik, siyasal, mahrem, etik, tüketime dair vs. görüşlerin paylaşıldığı bir mecra olduğundan katılımcıları her boyutta etkilemektedir. Sosyal medyadaki dil de bu sebeple büyük önem arz eder. Pek çok kısaltma ve İngilizce öğeler kullanılarak yapılanan bu dil, küresel dünyanın ortak dili İngilizceden çok fazla kelime almıştır. Bu kelimeler diğer dillerde olduğu gibi Türkçeye doğrudan geçmiştir. Bunun en büyük sebeplerinden biri yeni medyanın evrensel ortak dili ve teknolojinin hızl gelişimidir. Bir kelimenin toplum tarafından kabulü uzun ve halk onayına bağlı bir süreçtir. Örneğin "selfie" kelimesi çok popüler ve yaygın bir biçimde kullanılmaya başladığında Türk Dil Kurumu bunun için "öz çekim” kelimesini Türkçeye katmış olsa da, halk dilinde hala "selfie" kelimesi kullanılmaya devam etmektedir. Çünkü sosyal medya tüm dünyada evrensel diliyle var olmaktadır ve o dil kullanıldığında iletişim daha hızlı ve kolay gerçekleşmektedir. Hatta her bir platformun oluşturduğu kendi dili ve daha sonra ortak kullanımda da popüler olan kelimeler de mevcuttur. Örneğin "tweetlemek", "retweetlemek", "trend topic (TT)" gibi sadece Twitter'a özel kelimeler, ya da ortak kullanımda olan "mention”,"hashtag”, "direct message (DM)", "forwardlamak", "fenomen olmak", "chatleşmek", "trollemek"gibi. Örnekte de görüldügü üzere kelimelerin hiçbiri Türkçe türevli olmayıp İngilizceden gelen kelimelerdir. Sosyal medya platformlarının menşei çoğunlukla Amerika olsa da, sonraki yllarda popülerliğini Amerika dışındaki ülkelerden edinmiştir. Kullanıcıları çoğunlukla Amerika dışındadır. Her ne kadar tüm sosyal medya platformları, kullanıcılarına kendi dillerinde ara yüz sunsa da kullanılan kelimelerin çoğu menşeinden gelen dildedir. Ayrıca bu araştırmada da bazı sosyal medya platformlarının ara yüzlerinin kitle çevirisi metoduyla erek dile çevrilmesi üzerine çalışılmıştır.

Sosyal medyada dil dışı göstergeler, imojiler de iletişimde önemli bir yer tutmaktadır. Bu semboller ayrıca duygu da içerdiğinden dil kadar etkin ve ifade de önem taşıyan konumdadır. Sosyal Medya günümüzde sadece eğlence ya da vakit geçirme platformu olmadığından iş dünyasında da aynı etkinlikte kullanılmaktadır. İş dünyasında kullanılan dil, ana akım medyaya yakın olsa da dijital dil 
yine de etkindir. Teknolojik gelişmeler aynı hızda devam ettiği sürece de sosyal medyada kullanılan ortak dil küreselliğini korumaya devam edecektir.

\subsection{Sosyal medya katılımcı kültür ve üretüketici}

Sosyal medya platformları, yeni medyanın yayılabilirliğini maksimuma çıkarmıştır. Yeni medyanın çok önemli bölümünü kapsayan sosyal medya, Web 2.0 tabanlı dijital bir platformdur ve içeriği kullanıcılar tarafından oluşturulan ve kolayca ve kısa zamanda çok kişinin görebileceği şekilde paylaştırılan sanal topluluklardır. Web 2.0 öncesinde interaktif olmayan sosyal medya platformları kullanıcıları, Web 2.0 ile birlikte edilgen yapıdan etken yapıya geçiş yapmış, böylelikle internet kültürü, popülarite ve tüketim kavramları tamamıyla değişmiştir. Sosyal medyanın zaman ve mekândan muaf yapısı, her kesimden insana açık oluşu, az maliyetle geniş kitlelere kısa zamanda ulaşabilme özelliği, düzeltmelere her daim izin veren yüze sahip olması onun küreselliğini sürdürülebilir hale getirmiştir. Dinamik yapısı ile sürekli yeniliklere açık yapısıyla sosyal medya, her internet kullanıcısını birer içerik üretici haline getirmiştir. Kolayca içerik oluşturabilen etken kullanıcılar, sosyal medyanın katılımcı kültürünü, ortak dilini oluştururlar.

Eş zamanlı etkileşimi minimum sürede sağlayan bu platformda gerek özel gerek ticari faaliyetleri gerçekleştirmek en kolay haliyle kullanıcıya sunulmuştur. Enformasyon dağılımının hızı ve küreselliği tartışlamaz şekilde diğer platformlardan ayırt edicidir. Yalnızca tüketime değil üretime de etkin şekilde yer veren, günümüzde pek çok kurumun iş stratejilerini kurdukları, firmaların olmazsa olmazı haline gelen bu platform, oylama, yorumlama, katkıda bulunma, paylaşma, çift yönlü etkileşme, kısa sürede ortak paydada topluluklar oluşturma, reklam yapma, satın alma, satış yapma, vs. gibi özellikler barındırmaktadır (Brown, 2009: 32).

Özgür iletişim olarak da anılan sosyal medya, Castells'e göre bir yandan da mahremiyetten vazgeçme, hedefli reklam olma karşılığında küresel iletişim ağlarına erişimi insanlara satma ile sonuçlanır (Castells,2009: 421). Her ne kadar erişimin amacı Web 2.0 ticaret stratejisinde satış değilse de, kullanıcıları üre-tüketici haline getirerek metalaşmasını sağlar ve üçüncü kişilere satar. Örneğin, Facebook'taki bilgilerin diğer sosyal medya platformlarında da kullanılabilmesi gibi. Sosyal medya günümüzde özellikle içinde bulunduğumuz pandemi döneminde o kadar büyük bir güce sahip oldu ki, küçük yaştan büyüğe herkes bu platformların etkisi altına girdi. Couldry, medya gücünü, gerçekliği inşa etmenin simgesel gücünün medya kuruluşlarındaki yoğunlaşması olarak tanımlar (Couldry, 2002: 4). Bu tanıma göre, sosyal medyanın elinde bulundurduğu güç, simgesel ve kültürel boyutları ile irdelendiğinde, içeriğin üretimi, yayılımının hızı ve çokluk boyutu, hem bireysel hem de topluluk hâlinde etkileşimlere, dolayısıyla siyasal, ekonomik ve ticari açıdan büyük önem arz eder. Kendi kuralları ile yeniden şekillenen bir topluluk, bununla birlikte evrensel bir kültür oluşturur. Ekonomik açıdan bakıldığında, sosyal medya, kendi içinde üretilen dağıtılan ve tüketilen kullanım değerleri ve kaynaklarının denetimini, para ve sermaye denetimini belirler. Kültürel açıdan bakıldığında, toplumda neyin önemli, değerli, saygın, kıymetli ya da değersiz, linç edilesi olduğunu şekillendiren dijital ahlaki değerler ve anlamlar tanımını, siyasal açıdan bakıldığında ise ifade özgürlüğünü, adil haberciliği, alternatif haber kaynakların belirler (Fuchs,2016: 113). Kültürel, siyasal ve ekonomik medya gücünü elinde bulunduran sosyal medya gücünü ise kullanıcılarından alır.

Kullanıcıların ürettikleri içeriklerle hem üretici hem tüketici konumunda olmaları ve sosyal medyanın anında etkileşimli iletişim gücü, saf üretim ve saf tüketim faaliyetlerini bulanıklaştırdığı bir yapıya dönüşür (Toffler,2008: 358). İlk olarak Toffler’in tanımıyla kullanılan üre-tüketici kavramı, Ritzer 
tarafından da ele alınmıştır. Ritzer'e göre üre-tüketimin başlangıcı Endüstri Devrimi’nden itibaren olduğundan ve ayrımın bu zamandan itibaren kesin çizgilerle belirlenmemiş olduğunu düşündüğünden kavramı "Üretim Çağı" ve buna post modern akışkan toplumun ekonomik boyutlarından biri olarak değerlendirmiştir. (Ritzer, 2015: 414). Sosyal medya tüketimin en önemli boyutlarındandır; bu sebeple de içeriğinde kullanılan dilin evrenselliği, içeriğin anlaşılırlığı büyük önem arz eder. Üre-tüketici formatındaki ikili kod ve onun oluşturduğu kültürel pratikler çok geniş bir enformasyon ağı ve tüketim mecrası oluşturmuştur. Kullanıcı odaklı tüketim içerikleri, hem dijital popüler kültürün oluşumunda hem de katılımcı kültürün şekillenmesinde meta oluşumuna odaklanmıştır. Tüketim merkezli popüler kültürün altın çağına yön veren sosyal medya platformları, maddi olmayan üretim ve maddiyat odaklı tüketim alışkanlıklarının boş zaman üzerinden harmanlanmasına evrilmiştir.

İlk zamanlarda boş zamanı değerlendirmek üzere düşünülen sosyal medya platformları zaman, emek, mahremiyet ve etik tüketiminin gönüllü mecrası haline gelmiştir. Anlam üzerine kurulan bu meta, düşünülenin aksine sosyal medya mecralarında tüketilebilen bir meta halini almıştır. Öyle ki, bu mecrada oluşturulan her türlü veri akışıyla kullanıcılar, farkında olarak ya da olmayarak, öznel ve kar amacı gütmeyen paylaşımları, beğenileri, linçleri ve yorumlarıla tüketim yaratma amaçlı medya aktörlerinin ihtiyacı olan bilgileri elde etmektedirler. Böylelikle boş zaman geçirmek için girilen ve aynı anda içerik üretilen bu platformlar, üretici pozisyonunda da kullanıcıları değerlendirmiş olmaktadırlar ve üreten- tüketen ayrımı ortadan kalkmış olmaktadır. Kullanıcının bu durumda yaratmış olduğu ve karşllığı ödenmemiş ya da ödenmiş her türlü emeğe "dijital emek" denmektedir (Fuchs, 2015: 15). Fuchs'un Dallas Smythe’nin "izleyici emeği” üzerinden tanımlandırıldığı, televizyon izleyicisinin emeği ile bugünkü internet kullanıcısının emeğini benzeştirdiği "dijital emek" kavramı, kullanıcı açısından farklılıklar içerir. Sosyal medya mecralarında içerik oluşturarak o mecranın sürdürülebilirliğini devam ettiren üre-tüketici, geleneksel medya izleyicisinden farklıdır. Sürekli olarak iletişim akışını sağlayan, kültürel aktarıma katkıda bulunan, toplum inşasında aktif rol alan sosyal medya kullanıcısı aynı zamanda katılımcı kültürü de oluşturan güçtür.

Katılımcı kültür, sosyal medya platformlarında kullanıcıların içerik ve kültür yaratmaya dâhil olması anlamında kullanılır. Geleneksel medyada kültür aktarımı tek taraflı iken, sosyal medyada kullanıcıların kültürü oluşturmadaki katkısı yadsınamaz şekildedir. Bruns üretim ve kullanımın (üretlanım) sözcüklerle anlam kazanımıyla sosyal medyanın oluştuğunu savunur (Bruns,2008: 256). Sözcükler ve ifade biçimleri ile şekillenen katılımcı kültür daha demokratik bir yapıya sahiptir. Ana akım medyaya göre daha özgür platformlarda düşüncelerini, isteklerini ve hoşnutsuzluklarını bildiren ve kendileriyle aynı düşüncede insanlarla, ortak paydalarda buluştukları gruplarda daha öznel, daha bireysel etkileşimlerde bulunabilen katılımcılar için sosyal medya platformları bireye kendini daha özel hissettirir. Geri dönütü anında alınabilen, bireyin kendini gerçekleştirmede en üst düzeyde hizmet veren ve kolay kullanılabilen sosyal medya platformları, internetin cep telefonlarına erişimi ile çok daha popüler ve kullanılır hale gelmiştir. Artık boş zamanı ya da sıkılacak vakti hiç olmayan birey, gerek boş zamanında gerek çalışma vaktinde gözünü sosyal medya platformlarından alamaz hale gelmiştir.

Jenkins'e göre katılımcı kültür, insanların ă̆ üzerinden buluşarak ortak paydada etkileşim haline gelmesidir (Jenkins,1992: 25). Fakat Jenkins'e gelen en büyük eleştiri ise bu kültürün sadece pozitif yönlerini ele alması ve sınıf ve maddi çıkarın bölüşümü ya da mülkiyet gibi kavramlar açısını yok saymasıdır. Katılımcı kültür adı üstünde olarak aktif kullanıcının katılımıyla kolektif yapılan işler, faaliyetler ve çoklu görevlendirmeyi de içerir. Facebook, Twitter, Wikipedia, Google gibi güçlü ve ticari 
sosyal medya platformları, katılımcı kültürün dağılımı, paylaşımı, üretimi ve tüketiminde büyük aracı rolü almaktadırlar. Katılımcılar her ne kadar içerik üretiminde, tüketimde önemli rol alsalar da aracı olan bu şirketlerin ekonomik karar alma süreçlerine karışamazlar. Katılımcllık süreleri boyunca içeriklerinden belirli bir düzeyde kar eden kullanıcılar olsa dahi, var olma sebepleri ile bu büyük sosyal medya platformlarının karlarına hizmet ederler. Katılımcı kültürün ne kadar katılımcı olduğu bu platformların belirledikleri sınırlara göre çizilmektedir. Bu platformlarda var olmayan diğer şirketler, hatta ana akım medya kuruluşları, kurumlar, bireyler, sanal dünyada var olamadıklarından dijital kimlikleri oluşamamıştır. Tüm dünyanın, kimlikleri ararken, sosyal medya platformlarından araması, anlamlandırması, bu platformlarda var olmayanın dışlanması anlamına da gelmektedir. Son senelerde de görüldüğü üzere sosyal medya platformları üzerinden var olmayan şirketler reklamlarını eksik yapmış, istediği hedef kitleye ulaşamaz hale gelmiştir. Bunun sebebi dijital kimlik oluşumunun tüm dünyadaki önemidir. Aslında bir yönden de kapitalist sistem kendini dijital dünyada sosyal medya platformları üzerinden eskisinden de güçlü bir şekilde devam ettirmektedir. Yani katılımcı kültür de büyük ölçüde şirketler tarafından mülk edinilir, denetlenir ve organize edilir. Sosyal medya kültürü bir kültür endüstrisidir (Fuchs,2016: 83). Katılımcıların kendi arzularıyla meta haline geldiği bu platformlardaki en önemli sorunsal ise bu büyük şirketlerin sosyal medya kullanıcılarını, katılımcı kültür oluşumunda üre tüketiciler aracıllğ̆ ile meta haline getirip getirmemesidir.

\subsection{Kitle kaynak kullanımı ve sosyal medya örnekleri}

Bu çalışmada katılımcı kültürün ve üre tüketicilerin tüketim bağlamında meta haline gelişi ve grup çalışması örneklerini verirken, sosyal medyadaki kitle kaynak kullanımı (crowdsourcing) ele alınmıştır. Kitle kaynak kullanımı, çoğunluğun katılımı ile büyük bir işi parçalara bölerek yapılma eyleminde kullanılan bir kolektif çalışma biçimidir. Sosyal medya platformlarıyla üstün gelişmeler gösteren bu kullanım, şirketlerin dış kaynak kullanım amacıyla ortak kullanılan hesaplarda yapılan duyurularla aktarılmasıdır (Howe,2008: 31) . Jeff Howe'un ortaya attığı bu katılım, zamandan ve mekândan muaf olunduğundan sosyal medya ile etkin bir yardımlaşma aracına dönüşmüştür. Enformasyon akışkanlığının çift yönlü ve andaş olması sebebiyle sosyal medya platformları kitle kaynak kullanımı ve kitle kaynak çevirisinin aktif şekilde işlemesi için en uygun platformdur. Gerek iş gerekse eğlence amaçlı kullanılan kitle kaynak kullanımı, yardımlaşmadan ekonomik verilerin dağılımına kadar pek çok yönde katılımcıların kolektif çalışmalarına katkı sağlamış, ihtiyaç duyulan bir hizmeti daha kısa zamanda elde etmeyi vaat eden bir yapıya sahiptir.

$\mathrm{Bu}$ yeni ve son derece yenilikçi çalışma yönteminin getirdiği değişiklikler, çeviri sektörünü de etkilemiştir. Kitle kaynak kullanımı yalnızca çeviri uygulamasını değil, aynı zamanda çeviri teorileri ve bu faaliyetin algılanma şekli üzerinde de etkisini göstermiştir. Özellikle, bir faaliyete çok sayıda insanı dâhil ettiğinden, o faaliyetin tanınırlı̆̆ını ve görünürlüğünü geliştirmeye de yardımcı olan bir eylemdir. Kitle kaynak kullanımının yaygınlaştığı diğer alanlarda olduğu gibi, işin gerçekleştirilme şekli kolektif olarak yürütüldüğünden, çevirmenlerin mesleki gelişimlerinde hem grup çalışması olarak hem de bireysel gelişim açısından çok önemlidir. Bir diğer yandan düşünülenin aksine kitle çevirisi çevirmenlik mesleğini sekteye uğratmayı değil takım halinde çalışmanın önemine vurguda bulunarak bireysellikle çokluğun uyumunu dengeleyip çevirmene deneyim kazandırır.

Firmaların hiçbir zaman sahip olamayacağı insan gücüne sahip olan ve dünyanın her bir yanından katılıma sahip kitle kaynak kullanımı az maliyetle hatta maliyetsiz bir şekilde daha az zamanda daha çok işi çok fazla sayıda kişiye dağıtmak paylaşım ekonomisinin temellerini de atmaktadır. Şirketlerin yeni trendi de diyebileceğimiz bu uygulama topluluk kaynaklarını en iyi kullanan sosyal medya 
platformlarında çığır açmıştır. Topluluk ekonomisine de bakıldığında, insanların boş zamanlarını daha efektif ve topluma katkı sağlayacak şekilde geçirmelerini de sağlayan bu kullanım, gerçek hayatta bir araya gelmesi mümkün olmayan kombinasyonlarla insanları bir işin odağında hem de gönüllülük esasına dayanarak toplamıştır.

İşbirlikçi odaklı çalışma yollarının etkin kullanıldığı sosyal medya platformlarındaki gelişmeler, Avrupa Komisyonu'nun da ilgi odağı haline gelmiştir. Her ne kadar temkinli yaklaşlan bir yöntem olsa da, kitle kaynak kullanımı ve çevirisi pek çok büyük projenin kısa zamanda üstesinden gelinmesini sağlamıştır. Sosyal medya kullanıcılarına küçük çapta da olsa ek gelir sağlamış ya da ücretsiz emek olarak düşününce de deneyimsiz kişilerin kendi uzmanlık alanlarında deneyim kazanmalarına, takım çalışmasına uyum sağlamasına imkân tanımıştır. Şimdiye kadar kar amacı gütmeyen kuruluşlar, işletmeler kurumsal kuruluşlar kitle kaynak kullanımını geçici bir popüler akım olarak görseler de, iş bölümü ve büyük çapta bir işin bölüşülmesi ile az maliyet de göz önünde bulundurulduğunda bir yeni sosyal medya gerçekliği daha gözler önüne serilmiştir.

"Kitle kaynak kullanımı" terimi, Jeff Howe tarafından 2006 yılında "kitle" ve "dış kaynak kullanımı" (outsourcing)in birleşimi olarak kullanılmıştır. İlk defa Wired dergisi makalesi "The Rise of Crowdsourcing"'de kullanmıştır. Howe, teknolojinin hızlı ve yadsınamaz gelişimi ile iş dünyasında amatörler ve profesyonellerin arasındaki uçurumun azaldığını ve şirketlerin sosyal medya kullanıcılarının (çoğunluğun-kitlenin) işgücünden yararlanması gerektiğini savunmaktadır (Howe,2008: 23). Henk'e göre ise kitle kaynak kullanımı şirketlerin ya da kuruluşların bir sorunsalı çözmek adına sosyal medya platformlarında katılımcılarla paylaşması ve sorunun çözümüne çoğunluğun gücü ile cevap bulmasıdır (Henk,2010: 3). Aslında geçmişte de kullanılan bu teknik hem amatör ruhu yaşatmada hem de kısa sürede çözüm odaklı çalışmaya imkân vererek kazan kazan formüllü bir dayanak da sağlamış olmaktadır. Bir yandan amatöre firsat tanırken diğer yandan da kitle kaynak kullanımının en önemli faktörü olan topluluğun rolüne dikkat çekmektedir. Çoğunluğun bireyselden daha güçlü ve muhakeme yönünün çok yönlü olduğu yönündedir (Surowiecki,2004: 13).

Bu oluşan kitle kaynak kullanımına gönüllük esasına dayanarak katılan katılımcılar, tıpkı sosyal medya platformlarında bir konunun ele alınıp yorumlar yapılarak o konu hakkında çözüm arandığı gibi, kendi bilgi ve yeteneklerini başkaları ile paylaşma firsatı bulur ve gerçek hayatta karşlaşamayacağı iş fırsatını bu katılım görevi aracılığı ile deneyimler. Bu yönüyle geleneksele göre daha demokratiktir ve çalışanı çok daha iyi motive eder. Alınan ödül genelde özgüven ve saygı üzerine kurulmaktadır. Sosyal medya platformlarının katılımcı kültüre en büyük etkisi ve sağladığı motivasyon bu platformlardaki kimlik oluşumu olduğu için, kitle kaynak kullanımı da Marx’n artı değerine en uygun kazançlardan biridir. Çünkü sosyal platformlardaki benlik algısı, kimlik inşası faaliyetleri kazanılacak paradan daha kıymetlidir. Kitle kaynak kullanımına en güzel örneklerden bir tanesi gönüllü haberciliktir. Kitle kaynak kullanımı ile sadece akıllı bir telefonla, profesyonel ve çok donanımlı bir haberciden çok daha fazla sayıda gündeme gelebilecek haberleri kitle katılımı ile sosyal medyada anında dă̆ıtma ve yayma özelliğine sahiptir. Hatta bu amatör haberciler, ana akım medyanın "What's up ihbar hattı" ya da trafik hattı gibi çeşitli habercilikle, andaş katılımcılarla çok yönlü ve çeşitli haber oluşturmada yardımcı olur.

Sosyal medya platformları çoğunluğun sesi olarak günbegün yükselerek katılımcı kültürünü oluşturmaya devam etmektedir. Verilmek istenilen mesajların tüm dünyaya aynı anda verilebilmesi ve çoğunluğun gücü ile dünyada iyi ya da kötü tüm enformasyonun sürekli olarak akışı kitleler için her zaman çekici olacaktır. Bu platformlar, kitle gücünü arkasına alarak popüleri oluşturmaya ve tüketim faaliyetlerine yön vermeye devam edecektir. 


\subsection{Kitle çevirisi ve örnekleri}

Kitle Çevirisi de sosyal medya platformlarında yaygın kullanılan ve gelişmekte olan bir çeviri yöntemidir. Sosyal medyanın boş zamanla çalışma saatlerini bulanıklaştırması gibi kitle çevirisi de kadrolu çevirmenle stajyer çevirmen arasındaki farkı bulanıklaştırmaktadır. Her zaman yeniliklere açık olan sosyal medya, kitle çevirisine öncülük ederek, kısa zamanda büyük işleri bitirmeye ve geri dönüt olarak da yine sosyal medya katılımcılarını kullanarak düzenlemelere müsaade eden yapısı ile hem çeviri işini hem de kontrolünü katılımcıları ile tamamlamıştır.

Diğer meslekler gibi yeni medyada var olamayan hiçbir meslek, içinde bulunduğumuz dönemde tam anlamıyla sürdürülebilir olamayacaktır. Çevirmenlik mesleğinin de yeniden yapılandığı bu dönemde bilgisayar tabanlı çeviri motorları maliyetsiz olduğundan çok kullanılmaktadır. Hemen hemen tüm sosyal medya platformlarının kendine özel çeviri motoru bulunmaktadır. Fakat anlam bütünlüğünün tam olarak korunamadığı, yapay zekâ çevirileri insan zekâsıyla gerçek anlamda yarışamamaktadır. Daha çok teknik çeviri ve iletişim ve kısa cümleler ya da kelime odaklı çevirilerde genel anlamı kavramak adına kullanılmaktadır. Çevirmenler için büyük bir iş kaybı olacağı düşünülse de, sektörde duygusal ya da mantıksal zekâya her zaman ihtiyaç vardır (Üründü,2018: 187). Örneğin, sosyal medyada kullanılan, "durum" bölümlerinde "çevir" butonuyla diğer katılımcıların içerik üretimlerini, duygulanımsal paylaşımlarını erek dilde de görebilen katılımcılar, başka dilde de diğer katılımcılara yorum yapabilir, aynı gönderiyi paylaşabilir durumdadır. Dilin evrenselliği sosyal medyada da çeviri motorları ile sağlanmaktadır. Bu çevirilerin en işlev hali ise anında diğer bir kullanıcı tarafından geri dönüt alarak düzeltilebilir olmasıdır. Bu sayede hem çeviri hem de düzeltmeler katılımcılar tarafından yapılır, sosyal medya platformunun iş yükü azalır, hatta sıfıra iner. Aynı içerik oluşturmada bahsi geçen üre tüketici katılımcı, çeviride de kitleden faydalanır. Ayrıca büyük şirketlerin bu kitle çevirmenleri arasından en iyilerini seçmeleri ve çevirileri düzenlemeleri adına Topluluk Çeviri Yöneticileri bulunmaktadır. Bu yöneticiler iyi çevirmenlerin şirketlerinin bünyesine kadrolu çevirmenler olarak alınmalarını sağlamaktadırlar (188).

$\mathrm{Bu}$ çalışmada kitle çevirileri Google, Wikipedia, Facebook ve Twitter üzerinden tartışlacağı için örneklendirmeler de onlardan alınmıştır.

\subsubsection{Google ve kitle çevirisi}

Google dünya çapında en çok tercih edilen en eski ve en köklü arama motorudur. 2019 yllı istatistiklerine göre dünya çapında \%87.96 tıklanma oranıyla diğer arama motorlarını geride bırakmıştır². Sitelerin etkileşimli bağlantılarını ve sonuçlarını çözümleyerek kullanıcıların istedikleri bilgiye daha etkin, daha kolay ve daha kısa sürede ulaşmaları için bir aracıdır. Google arama motoru Türkiye'de de gündelik yaşamımızın en önemli yapı taşı olmuş durumdadır. "Googlelamak" kelimesi pek çok dilde yerini almış, yeni medyada bir bilgi aranmak istediğinde ilk önce Google’a başvurulduğundan bu kelime yerini bulmuştur3.

1998 yllında Larry Page ve Sergey Brin tarafından kurulmuş olan Google, 2004 yllında halka arz edilmiştir. 2006 yllında da YouTube' u, 2008 yllında da DoubleClick’i satın alarak büyümeye devam etmiştir. (Vise,2005, s.4). Hedefli, gözetime dayalı reklamcılık ve tıklanma sayısı ile gücüne güç katan Google, bir tür ekonomik gözetim modeli olduğundan ve geleneksele göre daha kesin rakamlarla

https://ppcprotect.com/google-search-statistics/

https://www.oxfordlearnersdictionaries.com/definition/english/google

Adres

Kırklareli Üniversitesi, Fen Edebiyat Fakültesi, Türk Dili ve Edebiyatı Bölümü, Kayalı Kampüsü-Kırklareli/TÜRKIYYE e-posta: editor@rumelide.com
Kurklareli University, Faculty of Arts and Sciences, Department of Turkish Language and Literature, Kayalı Campus-Kırklareli/TURKEY e-mail: editor@rumelide.com 
istatistik veriler vererek, bu özgür yeni medya platformlarında panoptikon sistemin ağlarını emin adımlarla örmüştür. Google gücünü asıl üre tüketicilerinden alır. Gönüllük esasında artı değer üreten kullanıcılar bu platforma değer kazandıran sermaye döngüsünü canlı tutan metalardır. Dünya çapında kullanılan Google Maps, Google Translate, Google Earth, Google Print, YouTube, Google+, Gmail ile kullanıcılarına hizmet veren Google, "çok kullanıcı çok veri” mottosu ile kitle kaynağı en aktif kullanan motordur. Her ne kadar yapay zekâ üzerine kurulu bir çeviri motoru bulunsa da, bu uygulamasının düzenlemeleri yine kitle kaynak çevirisi yöntemi ile yapılanmaktadır. İlk olarak 2006 yllında Arapça ve İngilizce olarak hizmete başlayan Google Translate ücretsiz olup, şu anda 10o'den fazla dili desteklemektedir. Google Nöral Makinesi Tercümesi ile örnek tabanlı makine çevirisi olarak çalışır. Çeşitli kombinasyonlarda kaynak dil önce İngilizceye sonra istenilen dile çevrilerek kullanılmaktadır. Google, 25 Ağustos 2016 tarihinde Google Çeviri motoruna düzgün bir dizgileme getirebilmek için kitle kaynak çevirisini kullanıcılarına açmıştır. Gönüllülük esasına dayalı bu metot, kullanıcılarına çevirileri anında düzenleme ve düzeltme olanağı sağlar (Alkan- Canım,2017: 72).

\subsubsection{Wikipedia ve kitle çevirisi}

Wikipedia bir dijital ansiklopedi olup tam olarak bir kitle kaynak kullanımı ve çevirisi üzerine yapılanmıştır. Dünyadaki pek çok insanın bilgi için arama motorunu tıkladıklarında ilk karşısına çıkan sosyal medya platformudur. Türkiye'de de Google arama motorunda enformasyon için tıklandığında ilk karşılaşılan seçenektir. Her ne kadar büyük eleştiriler alsa da, katılımcılar tarafından çok kullanılan, hem içerik oluşturulan hem de bilgi tüketilen bir platformdur. Tamamen kitle kaynak kullanımı ile şekillenmiştir. Hemen hemen tüm dünya dillerinde kaynağı vardır.

"Wikipedia" kelimesi "wiki” ve "pedia" kelimelerinin birleşiminden oluşmuştur. "Wiki”,Hawai dilinde hızlı anlamına gelmektedir; "pedia" kelimesi ise "encyclopaedia" kelimesinin son hecesinden alınmıştır. Birleşimi hızlı erişilebilir ansiklopedidir. İlk yayınlanan çevrimiçi ansiklopedia 2001 yllında Jimmy Wales ve Larry Sanger tarafindan kurulan ve geleneksel bir yapıya sahip olan "Nupedia"dır. Daha sonra kurucuları "Nupedia" yı sosyal medya platformlarına ve çağa uydurarak, katılımcıların yorum yapabileceği ve içerikleri düzeltip düzenleyebileceği, kopyalayıp dağıtabileceği "Wikipedia" halinde kullanmayı tercih etmişlerdir (Kittur, 2006). Topluluk Çeviri Yöneticileri tarafından kontrol edilen, kısa zamanda kitle kaynaklı enformasyonların pek çok dile çevrilmesiyle yoğun bir şekilde kullanılan bu platform, "Nupedia" iken pek çok makale ve uzman yazınları içerdiğinden içerik oluşumda onlar da kullanıcı yorumları ve düzenlemeleri ile harmanlanmıştır. Bu platformun popülaritesinin artmasının ve dünya çapında arama motorlarında birinci sıraya oturmasının sebebi platformu katılımcılara açmasıdır. Platform sosyal medyanın popüler ve en çok aranan motorlarından olduktan sonra, çeviri yöneticileri de kullanıcılarının düzeltme ve düzenleme bölümünde gönüllü çalışan katılımcıların en iyilerinden seçilmeye başlanmıştır. Böylelikle tam bir kitle katılım ile gönüllülük esasına dayalı çalışma örneğidir. Wikipedia topluluğu da denen katılımcıların uyması gereken beş esas kural şöyledir: Wikipedia bir dijital ansiklopedidir, tarafsızdır, herkesin kullanımına, değiştirmesine ve düzenlemesine açıtır fakat ücretsiz ve gönüllük esasına dayalı olduğundan hiçbir kullanıcı telif hakkı iddia edemez. Bu durum aslında pek çok sosyal medya platformları ve kullanıcı arasındaki ilişkilenmenin ve artı değerin tartışmalı kullanımı olarak görülmektedir. Yapılan yorumlar, tartışmalar saygı ve anlayış çerçevesinde olmalıdır; aksi takdirde editörleri tarafından müdahale edilir. Ancak açık kodlu yazılıma sahip olduğundan bilgisinin güvenilirliğini garanti edemez, bunun için yine kendi katılımcılarına güvenir. Diğer yandan da tıpkı dijital gazetecilikte olduğu gibi katılımcıları platformu sürekli güncel tutar ve bilgilerini yenileme işlemi geleneksele göre en fazla yarım saati bulacak kadar hızlıdır. Hızlı bilgi akışı, özet halinde güncel bilgi barındırışı, hemen hemen her dünya 
dilinde karşılığı ve katılımcılarıyla bu kadar popülaritesini sağlıyor ve taze tutuyor oluşu, onu bu kulvardaki sosyal medya platformlarından ve geleneksel ansiklopedilerden daha revaçta bir site yapmaktadır.

\subsubsection{Twitter ve kitle çevirisi}

Dünyanın en popüler haber alma platformu olan Twitter, bir mikroblogtur. Mikroblog, katılımclların sosyal medya platformları üzerinden çevrimiçi katılımcılarla kısa mesaj gibi anlık mesajlaşmaları anlamındadır. Kullanıcılar kendi profillerini oluşturarak bu platformda bir kimlik edinirler. Fark ise kimden mesaj alabileceklerini seçebilseler de, kimlerin onların mesajlarını alacaklarını kısıtlayamazlar (Murthy,2013, s.10). Twitter San Fransisco'da 2006 yllinda Jack Dorsey tarafindan web tabanlı mesajlaşma adına kurulmuştur. Çok popüler olsa da, 2011'e kadar hedefli reklamcllı̆̆a geçmemiştir. Tweet, retweet, fav, hashtag, trend topic (TT) gibi sosyal medya popüler kültür kelimelerini dünyaya kazandırmıştır. Bazıları diğer sosyal medya platformlarında ortak şekilde Twitter'dan ilham alınarak kullanılsa da, bazıları Twitter’a özel kalmıştır.

2010 yllı itibarıla de pek çok sosyal medya platformlu siyasi ayaklanmalara gebe olmuştur. (Arap Baharı gibi). İlk defa sosyal medya platformları bu ayaklanmalar sonrası resmi cezalar ve yaptırımlara maruz kalmıştır. Sanal örgütlemenin gerçek hayata yansıyabileceği ve kitleleri çok etkileyebileceği göz önünde bulundurulmaya başlanmıştır. Ayrıca küresel bir platformda Arap Baharı'nın tüm yazışmaları ve şekillenme biçimleri Twitter'dan görüntülenebilirken, Batı'nın da aktif şekilde bu duruma dâhil olduğunu yazılan tweetlerle gözler önüne serilmiştir (Murthy,2013: 112). Ayrıca Arap Baharı bir Arap halkı eylemi iken, Amerika menşeili bir sosyal platformda, Amerikalılar ve Avrupalılar tarafından her yönüyle incelenip ayrıntılarının gözler önüne serilmesi de düşündürücüdür (Van Dijck,2013: s.45). Katılımcı kültürün oluşumunun ve sosyal medya kitle katılımının gücü bu sayede fark edilmiş olup daha sonra sosyal medya platformlarına yasal düzenlemeler getirilmeye başlanmış, devlet de sosyal medya platformlarında var olması gerektiğini anlamıştır. Böylelikle sosyal medya platformlarda yeni bir kamusal inşa başlamış olmaktadır (46).

Siyasal alanla kamusal alanın kesiştiği Twitter'da 2009'dan beri ara yüzlerinin oluşumu ve diğer ülkelere açılımları için gönüllü kitle katılım çevirmenleri ile çalışmaktadırlar. Oluşturulan Twitter Çeviri Merkezi ile gönüllülük esasına dayalı Twitter katılımcıları, atılan tweetleri değil, ürünün kendisini çevirmektedirler. Şu anda Twitter İngilizce, Fransızca, Almanca, İtalyanca, Japonca, Korece ve İspanyolca, Endonezce, Arapça, Rusça, Portekizce ve Türkçe dillerinde hizmet vermektedir. Bu dillerin tümü Twitter Çeviri Merkezine dâhil edilmiştir; böylece çevirmenler güncellemeler konusunda da Twitter'a yardımcı olmaya devam etmektedir ${ }^{4}$. Multilizer Yerleştirme Aracı sayesinde, çevirmenler kolaylıkla Twitter'a kayıt olup kendi dillerini seçerek ister editörlük, ister çevirmenlik, isterlerse yerelleştirme yapabilmektedirler. Çeviri Merkezi'nin kontrolörleri de artık profesyonelleşen gönüllü katılımcılardan oluştuğundan Twitter tam bir kitle çevirmenlik ağı örneğidir. Özel çevirmen profili oluşturulmasına da izin verilen Twitter'da çeviriye yorum yapılıp üstünde düzenleme ya da çevirmene iletme butonları da kolay ve hızlı kullanımı ile hizmete sunulmuştur. Multilizer yerelleştirme araçları, MOTO (Multilizer Online Translation Outsourcing) şöyle çalışmaktadır:

Yazılım geliştiricisi, Multilizer'in yazılımı analiz etmesine ve yazılımın içindeki çevrilecek metni bulmasına izin verir. Multilizer çevrilecek metni İnternete yükler. Yazılım geliştiricisi kullanıcılarını /

https://blog.twitter.com/en_us/a/2011/translating-twitter-into-more-languages.html

Adres

Kurklareli Üniversitesi, Fen Edebiyat Fakültesi, Türk Dili ve Edebiyatı Bölümü, Kayalı Kampüsü-Kırklareli/TÜRKIYY e-posta: editor@rumelide.com
Kurklareli University, Faculty of Arts and Sciences, Department of Turkish Language and Literature, Kayalı Campus-Kırklareli/TURKEY e-mail: editor@rumelide.com 
çevirmenlerini çeviriye (web'de) katılmaya çağırır. Çevirmenler, kendi çevirilerini yazmak için web tabanlı Google Çeviriyi kullanır. Çeviri tamamlandıktan sonra, geliştirici Multilizer’in yazılımın çevrilmiş sürümünü oluşturmasına izin verir. Kitle çevirisi kullanımı, satışları genişletmek ve kullanıcı memnuniyetini artırmak için çok basit ve uygun maliyetli bir yöntemdir. MOTO ile yazılım çevirisi çok hızlı bir şekilde kitle kaynaklı hale getirilebilir5.

Kitle çevirisi, hem maliyet azlığından hem de kısa sürede büyük işlerin üstesinden gelmede çok etkili olduğundan popüler sosyal medya platformları tarafından gün geçtikçe daha çok tercih edilmekte, makine çevirisi özellikle kurumsal işletmeler tarafından tercih edilmemektedir. Dünya dillerinde yenilenen ara yüzleriyle tüm sosyal medya platformları daha küresel ve herkesi kapsayan hale gelmiştir.

\subsubsection{Facebook ve kitle çevirisi}

İlk kitle çevirisi denemesini yapan sosyal medya platformlarından biri de Facebook'tur ve Twitter gibi mikroblogtur. 2004 yllında Harvard Üniversitesi öğrencisi Mark Zuckerberg, Eduardo Saverin, Dustin Moskovitz ve Chris Hughes tarafından kurulmuştur. Reklamcllıktan ciddi gelir elde eden Facebook, 2012 yllında halka arz edilmiştir.

Sosyal medya platformu dendiğinde ilk akla gelen isimler, Facebook, Twitter veya Google gibi dünya çapında popüler ve katılımcı kültürün en fazla şekillendiği platformlardır. Sosyal medyanın doğası gereği kitle kaynak kullanımına çok müsait bir yapıdadır. Katılımcılar diğer platformlarda olduğu gibi hem yerelleştirmeyi, anında düzeltme ve değişim butonunu Multilizer Çervimiçi Araçlarını kullanarak daha kolay, kısa ve çabuk şekilde yapabilmektedirler. Twitter'da Google Çeviri Aracı kullanılırken Facebook'ta Microsoft'un Bing Çeviri Aracı ile çalışılmaktadır. Bilgisayar Tabanlı Çeviri araçlarını her ne kadar da iki platform da kullandırsa da ve öncelik hep bilgisayar çevirilerine verilse de, forum sayfasında yapılan oylamalarla duygusal zekâyı da arkalarına alarak kitle çevirmenleri bu çeviri araçlarından daha anlamlı çevirilere imza atmaktadırlar6 . Çevirilerin doğruluğunu sınamak için ayrıca bir forum sayfası da oluşturulmuştur. Orada çeviri için düzeltme yapılabilir, oylama yapılabilir ve saygı sınırları çerçevesinde tartışlabilir. 65’in üzerinde dilde hizmet veren Facebook ara yüzü, kitle çevirmenleri tarafından iki haftada İspanyolcaya, 24 saat içinde de Fransızcaya çevrilmiştir. İçeriğe ve oluşumuna katkıda bulundukları için katılımcılar bu platformla aralarından bağ kurmaktadırlar. Bu da Facebook'un hem kar etmesini hem de üre-tüketicilerini arttırmasını sağlar ki bu durum tam bir kazan-kazan durumudur7. Dahası Facebook bu bağı çeviri uzmanlığına göre verdiği ünvanlarla güçlendirmektedir. (Mayor, Blogger, Typesetter). Kimlik inşasının çok değerli olduğu sosyal medya mecralarında Facebook gibi önemli ve güçlü bir platform tarafından ünvanlandırılmak hem bir prestij hem de iş dünyası için iyi bir çevirmenlik deneyimi referansı olacaktır.

Sosyal medya platformları içinde de en eskilerden olan, satış ve hedefli reklamcılığı üretüketicileri ile çok iyi yürüten Facebook, birçok ticari sosyal medya aracının sermaye birikim stratejisinin merkezindedir. Her bir çevrimiçi faaliyeti, kullanım davranışını, kişisel veriyi takip eder, depolar, analiz eder, birleştirir ve reklam müşterilerine bunları pazarlar (Fuchs,2016: 233). Açık kodlu çalışılan ve diller arası akışkanlığı sağlayan kitle çevirmenleri de Facebook gibi büyük bir platformun ara yüzünü tüm dillere çevirerek, şirketi kara geçirmiş olmaktadır. Kendi bilgilerini de metalaştıran

http://translation-blog.multilizer.com/translation-crowdsourcing-translate-like-facebook-and-twitter/ http://help.multilizer.com/devzone/multilizer-online-translation-outsourcing/

https://coderslink.com/company/blog/learning-giants-google-apple-facebook-outsourced-development/

Kurklareli University, Faculty of Arts and Sciences, Department of Turkish Language and Literature, Kayalı Campus-Kırklareli/TURKEY e-mail: editor@rumelide.com 
kullanıcılar bunu gönüllülük esasına dayalı yaptığından artı değer mali kazanç içermemektedir. Fakat Facebook için her bir bilgi, ticaret aracıdır. (Fuchs,2012: 139). Büyük bir platform olduğundan ve diğer bazı küçük sosyal medya platformlarını satın aldığından, bazı oyun ve birçok yeni medya platformlarına yalnızca Facebook şifresi ile girilebildiğinden diğer platformlardan da verileri toplar ve onları birleştirerek analiz eder. Böylelikle kullanıcı tüketim faaliyetlerini kendi platformu üzerinden tanımlar (Fuchs,2016: 236). Sosyal medyanın en büyük tartışması olan gözetleme ve gizlilik ihlali, sosyal medya platformları için en büyük sorunsaldır; fakat üre-tüketicinin içerik oluşturma ve gizlilik modunu istediği gibi seçme seçenekleri, Facebook gibi büyük platformlar bu ihlalleri, katılımcının kendi tercihi diye lanse etmektedir.

\section{Araştırmanın amacı ve yöntemi}

Günümüzde çok yoğun kullanılan bilgisayar tabanlı makine çevirileri çok kısıtlı alanda kullanabilir olup, profesyonel işlerde yine çevirmenlere ihtiyaç duyulmaktadır. Çevirinin en önemli tercih sebebi kısa zamanda doğru işin yapılmasıdır. Sosyal medya platformları ellerinde bulundurdukları gönüllü katılımcılarının, üre-tüketicilerinin çeviri gücüyle ve yerelleştirmeye katkıları ile kısa zamanda çok iş başarıp, bu platformları çok dilli olarak yine katılımcılarına sunmuştur. Yeni medya odaklı şekillenen sanal dünyada önemli olan, işin doğru yapılmasının yanında, zaman ve mekândan muaf olarak çalışılıp, ücretsiz emekle, ya da az bir ücret karşılığında ve çok kısa sürede o işin bitirilebilir olmasıdır. $\mathrm{Bu}$ araştırmanın amacı, sosyal medya platformlarında sık kullanılan fakat akademik yönden az işlenen kitle kaynak kullanımı, katılımcı kültür ve kitle çevirmenliğinin tüketime katkısının Türkiye'deki yüzüne ışık tutmaktır. Dört güçlü ve köklü sosyal medya platformu, kitle katılımı ve çevirisi açısından incelenmiş olup kullanıcı etkisi de anket yöntemiyle araştırılmak istenmiştir. Verilerin elde edilmesinde anket yönteminden yararlanılmıştır.

\subsection{Araştırmanın evren ve örneklemi}

Araştırmanın Evreni, İstanbul'da bir vakıf üniversitesinin Yabancı Diller Yüksekokulu'nun ilgili bölümlerinin birinci, ikinci, üçüncü ve dördüncü sınıf öğrencilerinden oluşur. Araştırmanın örneklemi 2019-2020 Akademik Yılı Eğitim Öğretim Yılı Bahar döneminde okuyan 19-29 yaş aralığında ve rastgele gönüllülük esasına göre seçilen öğrencilerdir. Araştırmaya katılan öğrenci sayısı 120 kişi olarak belirlenmiştir.

\subsection{Araştırmanın sınırlılıkları}

Araştırmada katılımcıların 72'si kadın, 48’i erkek olmak üzere 120 kullanıcıdır. Her bir katılımcının herhangi dört sosyal medya platformunda hesapları olması esas alınmıştır. Anket, Türkiye'de 19- 29 yaş aralığında aktif sosyal medya kullanıcısının hem kitle katılımına ve katılımcı kültüre katkılarını ve tepkilerini saptamak, çeviri adaylarının kitle çevirisi bilgisini ve katkısını ölçmek, ayrıca 19-29 yaş aralığındaki tüketici alışkanlıklarını da göz önüne sermek üzere çalışılmıştır. Bu anket Kovid 19 pandemi döneminde yapıldığından sosyal medya platform katılımları fazlalığı ona göre değerlendirilmiştir.

\subsection{Veri toplama yöntemi}

Araştırmada veriler, pandemi dolayısıyla çevrimiçi olarak anket şeklinde gönderilmiştir. On üç sorudan oluşan anket yüz yirmi katılımcıya uygulanmıştır. Anket formunda bulunan soruların ilk iki sorusu cinsiyet ve yaş belirleme üzerine iken, üçüncü soru öğrenim durumunu sorgulamak için 
verilmiştir. Diğer on soru, kitle katılımı, katılımcı kültür, sosyal medya kullanımı, kitle çevirisi ve sosyal medya platformlarındaki tüketici alışkanlıkları ve popüleri belirleme üzerinedir. Anket soruları isim gizliliği esasına dayalı olup katılımcılar tarafından bireysel cevaplanmıştır. Anketin geçerliliğini ölçmek adına, sorular üç sefer farklı zamanlarda tekrarlanmış ve her defasında aynı cevaplar elde edilmiştir. Çalışma sonucunda elde edilen anket verileri SPSS 20.0'a girilerek analiz edilmiştir. Uygulanan program ile ankette yer alan Likert tipteki soruların güvenirliğini ölçmek için Cronbach'ın Alfa testi uygulanmış ve ortaya çıkan değer 0.8 olarak bulunmuştur. 10 sorudan, 2 tanesi 4 'lü Likert, 2 tanesi 2'li Likert, 6 tanesi ise 3'lü Likert olarak kullanılmıştır. Elde edilen verilerin istatistiklerini çıkarmak amacı ile soruların frekans ve yüzde dağılımları tablolar halinde gösterilmiştir.

\subsubsection{Veri analizi}

Araştırma 2019-2020 Akademik Yılı İstanbul'da bir vakıf üniversitesinin Yabancı Diller Yüksekokulu'nda öğrenim görmekte olan birinci, ikinci, üçüncü ve dördüncü sinıf öğrencileri ile gerçekleştirilmiştir. Yürütülen Sosyal Medya, Katılımcı Kültür ve Kitle Çevirisi adlı çalışmanın verilerinin toplanmasında anket yöntemi kullanılmıştır. Anket soruları genel anlamda katılımcı kültür ve kitle çevirisi, sosyal medyada tüketim konularına uygun dil ve anlam yapısındadır. Uygulama esnasında olumsuz etkileri en aza indirgemek için ifadeler ve terimler sözlü olarak da anlatılmıştır ve aynı sorular farklı şekillerde üç defa tekrarlanarak çalışmanın güvenilirliği ve geçerliliği denenmiştir.

Çalışmada kullanılan anket sıfırdan dizayn edilmiştir. Türkiye'de çalışılmamış, özgün bir konu olduğundan veriler çok değişkenli analize tabi tutulmuştur. Verilerin analizinde iki ikili, altı üçlü ve iki dörtlü Likert tipi ölçek kullanılmıştır. Anketin uygulanacağı kitle, araştırmanın hedef kitlesi ile uyumludur. Anket öncesinde ve sonrasında katılımcılar bilgilendirilmiştir. Katılımcılara; araştırmanın amacı, katılımcı onayı ve cevapların gizliliğinin korunacağı garantisi verilmiştir. Kendilerine bilgilendirme formu sunulmuştur. Çalışmada katılımcı olmak gönülllülük esasına dayandığından toplu form uygulamasına gidilmiştir. Katılımcılara katılımcı kültür ve kitle çevirisinin anlamı ve işlevi, örnek olaylarla kısa ve basit şekilde anlatılmıştır. Soruların da aynı basitlikte yalın bir şekilde olmasına özen gösterilmiştir.

\subsection{Bulgular}

Bu başlık altında anket uygulanan örneklem grubunun vermiş olduğu cevaplar ve bu cevaplarla ilgili bulgulara yer verilmiştir. Araştırmaya katılan tüm kullanıcıların, araştırmada çalışılan sosyal medya platformlarından en az birinde üyeliği vardır. Sosyal medya kullanıcıları olan katılımcıların yapılan anket çalışması sonucunda elde edilen bulguları aşağıdaki tablolarda gösterilmiştir. İlk üç tablo katılımcıların demografik özelliklerini belirlemek üzere hazırlanmış olup, diğer tablolar sosyal medya platformlarında kitle katılım, kitle çevirisi ve katılımcı kültürün tüketim alışkanlıkları ve popüleri belirleme tarzları üzerine yönelik hazırlanmıştır.

Tablo 1. Katılımcıların 19-29 yaş aralığındaki yaş dağılımı

\begin{tabular}{|l|l|l|}
\hline Geçerli & Frekans & Yüzde \\
\hline 2o yaş altı & 25 & 20.8 \\
\hline 20-25 yaş & 85 & 70.8 \\
\hline 25-29 yaş & 10 & 8.3 \\
\hline Toplam & 120 & 100 \\
\hline
\end{tabular}


Tablo 1. ankete katılan ve 19-29 yaş aralığında olan katılımcıların yaş dağılımını göstermektedir. Katılımcıların \%20.8'i 20 yaş altında, \%70.8'i 20-25 yaş aralığında ve \% 8.3'si 25 yaş ve üzerindedir. 20-25 yaş aralığındaki katılımcıların çoğunlukta olmasının nedeni katılımcıların üniversite öğrencisi olmalarıdır.

Tablo 2. Katılımclların cinsiyet dağılımı

\begin{tabular}{|l|l|l|}
\hline Geçerli & Frekans & Yüzde \\
\hline Kadın & 72 & 60 \\
\hline Erkek & 48 & 40 \\
\hline Toplam & 120 & 100 \\
\hline
\end{tabular}

Tablo 2 anketi yanıtlayan katılımcıların cinsiyet dağılımını göstermektedir. 72 kişi ile katılımcıların \%60'ı kadın iken 48 kişi ile katılımcıların \%40’ı erkektir.

Tablo 3. Katılımclların Öğrenim Durumu

\begin{tabular}{|l|l|l|}
\hline Geçerli & Frekans & Yüzde \\
\hline Lise & 106 & 88.3 \\
\hline Üniversite & 14 & 11.6 \\
\hline Toplam & 120 & 100 \\
\hline
\end{tabular}

Tablo 3’te katılımcıların eğitim durumuna ilişkin bilgi paylaşılmıştır. Katılımcıların \%88.3'ü lise mezunu olup aktif olarak üniversite de eğitim gören öğrencilerdir. Katılımcllarım 14’ü ise daha önce üniversite mezunu olup tekrar üniversitede okumakta olan katılımcılardır.

Tablo 4. Katılımcıların Facebook, Twitter, Wikipedia ve Google'da harcadığı süre

\begin{tabular}{|l|l|l|}
\hline Geçerli & Frekans & Yüzde \\
\hline o-2 saat & 2 & 1.66 \\
\hline 2-4 saat & 7 & 5.8 \\
\hline 4-6 saat & 41 & 34.16 \\
\hline $\begin{array}{l}\text { 6 ve } \\
\text { üzeri }\end{array}$ & 70 & 58.3 \\
\hline $\begin{array}{l}\text { Toplam } \\
120\end{array}$ & 100 \\
\hline
\end{tabular}

Tablo 4'te Katılımcılara gün içerisinde internete kaç saat zaman ayırdıkları sorulmuştur. Böylece \%1.66'sı 0-2 saat, \%5.8'i ile 2-4 saat, \%34.16'sı ile 4-6 saat, \%58.3’ü ise 6 saat ve üzeri seçeneği seçilmiştir.

Tablo 5. Facebook, Wikipedia, Google ve Twitter'da herhangi bir kitle katılımda bulundunuz mu ya da kitle çevirisi yaptınız mı?

\begin{tabular}{|l|l|l|}
\hline Geçerli & Frekans & Yüzde \\
\hline Evet & 40 & $33 \cdot 3$ \\
\hline Hayır & 55 & 45.8 \\
\hline $\begin{array}{l}\text { Kitle } \\
\text { katılımı }\end{array}$ & 15 & 12.5 \\
\hline
\end{tabular}




\begin{tabular}{|l|l|l|}
\hline $\begin{array}{l}\text { nı } \\
\text { bilmiyo } \\
\text { rum }\end{array}$ & & \\
\hline $\begin{array}{l}\text { Kitle } \\
\text { cevirisin } \\
\text { i hiç } \\
\text { duymadı } \\
\text { m }\end{array}$ & 10 & $\mathbf{8 . 3}$ \\
\hline Toplam & 120 & 100 \\
\hline
\end{tabular}

Tablo 5 verilerine göre, çevirmen adayı olan 120 katılımcıdan \%33.3’ü kitle çevirisi yapmış, \%45.8’i kitle çevirisi yapmamış, \%12.5’i kitle katılımı üzerine bilgi sahibi değil, \%8.3’ü ise kitle çevirisinin anlamını bilmemektedir.

Tablo 6. Facebook, Wikipedia, Google ve Twitter'da kitle çevirisinden para ya da unvan kazandınız mı?

\begin{tabular}{|l|l|l|}
\hline Geçerli & Frekans & Yüzde \\
\hline $\begin{array}{l}\text { Evet, unvan } \\
\text { ve/veya para } \\
\text { kazandım }\end{array}$ & 37 & 2.5 \\
\hline $\begin{array}{l}\text { Hayır, } \\
\text { unvan } \\
\text { ve/veya para } \\
\text { kazanmadım }\end{array}$ & 83 & 69.16 \\
\hline Toplam & 120 & 100 \\
\hline
\end{tabular}

Tablo 6 ya göre anket katılımcılarının \%2.5’i bahsi geçen sosyal medya platformlarda sunulan kitle çevirilerden unvan ve/veya para kazandığını, \%69.16'sı ise bu sosyal medya platformlarından ne para ne de unvan kazandığını belirtmişlerdir.

Tablo 7. Facebook, Wikipedia, Google ve Twitter’ın Türkçe arayüzü olması senin için önemli mi? İngilizce olsa aynı şekilde takip eder miydin?

\begin{tabular}{|l|l|l|}
\hline Geçerli & Frekans & Yüzde \\
\hline $\begin{array}{l}\text { Evet } \\
\text { onnemli }\end{array}$ & 84 & 70 \\
\hline $\begin{array}{l}\text { Hayrr, } \\
\text { Ingilizce } \\
\text { olabilir }\end{array}$ & 36 & 30 \\
\hline Toplam & 120 & 100 \\
\hline
\end{tabular}

Tablo 7’de katılımcılar İngilizce bölümlerde okumalarına rağmen, \%7o’i Türkçe ara yüzü, \%30’u İngilizceyi tercih etmişlerdir.

Tablo 8. Google Çeviri Motoru gibi bilgisayar tabanlı çevrimiçi çeviri araçlarının ilerde sizin mesleğinizi elinizden alacağını düşünüyor musunuz?

\begin{tabular}{|l|l|l|}
\hline Geçerli & Frekans & Yüzde \\
\hline $\begin{array}{l}\text { Evet } \\
\text { düşünüyorum }\end{array}$ & 68 & 56.6 \\
\hline Hayır & 41 & 34.16 \\
\hline
\end{tabular}




\begin{tabular}{|l|l|l|}
\hline düşünmüyorum & & \\
\hline Kararsızım & 11 & 9.16 \\
\hline Toplam & 120 & 100 \\
\hline
\end{tabular}

Tablo 8'de Anket uygulanan çevirmenlik öğrencilerinin \%56.6'sı, bilgisayar tabanl çevrimiçi çeviri araçlarının, çevirmenlik mesleğini ellerinden alacağını düşünmektedir; \%34.16'sı ise bunun doğru olmadığını düşünmektedir; \%9.16’lık bir kesim ise konu hakkında kararsız kalmıştır.

Tablo 9. Kitle Çevirisinin profesyonel olarak yapılan çevirmenlik mesleğine zarar vereceğini düşünüyor musunuz?

\begin{tabular}{|l|l|l|}
\hline Geçerli & Frekans & Yüzde \\
\hline $\begin{array}{l}\text { Evet } \\
\text { düşünüyorum }\end{array}$ & 35 & 29.16 \\
\hline $\begin{array}{l}\text { Hayır } \\
\text { düşünmüyorum }\end{array}$ & 77 & 64.16 \\
\hline Kararsızım & 8 & 6.66 \\
\hline Toplam & 120 & 100 \\
\hline
\end{tabular}

Tablo 9'da ankete katılan katılımcıların \%29.16'sı Kitle Çevirisinin profesyonel çevirmenlik mesleğine zarar vereceğini düşünmektedirler; \%77'si ise zarar vermeyeceğine kanaat getirmiştir; \%6.66'sı ise soru hakkında kararsız olduklarını belirtmişlerdir.

Tablo 1o. Ana dilinizde katıldığınız sosyal medya platformlarında içerik üretmek ve tüketmek sizce daha mı kolay?

\begin{tabular}{|l|l|l|}
\hline Geçerli & Frekans & Yüzde \\
\hline $\begin{array}{l}\text { Evet } \\
\text { düşünüyorum }\end{array}$ & 84 & 70 \\
\hline $\begin{array}{l}\text { Hayır } \\
\text { düşünmüyorum }\end{array}$ & 33 & 27.5 \\
\hline Kararsızım & 3 & 2.5 \\
\hline Toplam & 120 & 100 \\
\hline
\end{tabular}

Tablo 10'da ankete katılan katılımcıların \%70’i ana dilinde ara yüze sahip olan sosyal medya platformlarında içerik oluşturmanın ve içerik tüketmenin daha kolay olduğunu; \%27'si daha kolay olmadığını; \%2.5’i ise konu hakkında kararsız kaldıklarını beyan etmişlerdir.

Tablo 11. Ana dilinizde olan sosyal medya platformlarında alışveriş yapmak sizce daha mı kolay?

\begin{tabular}{|l|l|l|}
\hline Geçerli & Frekans & Yüzde \\
\hline $\begin{array}{l}\text { Evet } \\
\text { düşünüyorum }\end{array}$ & 86 & 71,66 \\
\hline $\begin{array}{l}\text { Hayır } \\
\text { düşünmmüyorum }\end{array}$ & 32 & 26.66 \\
\hline Kararsızım & 2 & 1.66 \\
\hline Toplam & 120 & 100 \\
\hline
\end{tabular}


Tablo 11'de ankete katılan katılımcıların \%71.66'sı ana dilindeki sosyal medya platformlarında alışveriş yapmanın daha kolay olduğunu, \%26.66'sı sosyal medyada ana dilinde alışveriş yapmanın daha kolay olduğunu düşünmediğini belirtmiştir. \% 1.66’sı ise bu konuda kararsız kalmıştır.

Tablo 12. Alışveriş Seçimlerinizi Sosyal Medya Platformlarına göre düzenler misiniz?

\begin{tabular}{|l|l|l|}
\hline Geçerli & Frekans & Yüzde \\
\hline Evet & 96 & 80 \\
\hline Hayır & 21 & 17.5 \\
\hline Kararsızım & 3 & 2.5 \\
\hline Toplam & 120 & 100 \\
\hline
\end{tabular}

Tablo 12'de katılımcıların sosyal medya platformlarındaki alışveriş seçimleri sorulmuştur. Katılımcıların \%80’i alışveriş seçimlerini sosyal medya platformlarına göre düzenlemektedir; \% 17.5’i alışverişini sosyal medyaya göre düzenlememektedir ve \%2.5’i bu konuda kararsız kaldıklarını belirtmişlerdir.

Tablo 13. Sizce popüleri sosyal medya platformları mı belirler?

\begin{tabular}{|l|l|l|}
\hline Geçerli & $\begin{array}{l}\text { Frekans } \\
\text { (n) }\end{array}$ & Yüzde \\
\hline Evet & 105 & 87.5 \\
\hline Hayır & 11 & 9.16 \\
\hline Kararsızım & 4 & 3.3 \\
\hline Toplam & 120 & 100 \\
\hline
\end{tabular}

Tablo 13’e göre katılımcıların \%87.5’i popüleri sosyal medyanın belirlediğini; \%9.16’sı belirlemediğini düşünmektedir. \%3.3’ü ise kararsız kalmıştır.

\section{Yorumlar}

Katılımcıların \%70.8’i 20-25 yaş aralı̆̆ındalardır. Kadın katılımcılar araştırmanın \%60’ını, erkek katılımcılar ise \%40’ını oluşturmaktadır. Katılımcılar üniversite öğrencisi olduğundan \%88.3’ü lise mezunu ve hali hazırda üniversite öğrencileridir. Katılımclların Facebook, Google, Wikipedia ve Twitter uygulamalarında harcadıkları süreye bakıldığında \%58.3'ü 6 saat ve üzerinde, \%34.16'sı 4-6 saat, \%5.8'i de 2-4 saat, \%1.66'sı ise 0-2 saat aralı̆̆ında sosyal medya platformlarında vakit geçirmektedirler. Böylece yaşadığımız pandemi sürecinde, özellikle 20-25 yaş aralığının, nerdeyse tüm günlerini sosyal medya platformlarında geçirdikleri gerçeği ile de yüz yüze kalınmıştır. Katılımcılara bu dört sosyal medya platformlarında herhangi bir kitle katılımında bulunup bulunmadıkları ya da kitle çevirisine dâhil olup olmadıkları sorulduğunda, katılımcıların \%33.3'ü evet, \%45.8’i hayır diye cevap vermiş, \%12.5’i kitle katılımını bilmediklerini, \% 80. 3’ü ise kitle çevirisini hiç duymadıklarını belirtmişlerdir. Yapılan ankete göre kitle katılımının kitle çevirisine göre daha çok bilindiği, fakat ikisinin de yeterince aktif kullanılmadığı anlaşılmaktadır. Kitle çevirisi yapmış olan katılımcılara da ayrıca Facebook, Twitter, Wikipedia ve Google'dan kitle çevirisi yaparak unvan ya da para kazanıp kazanmadıkları sorulmuştur. Katılımcıların \% 2.5’i para/unvan kazandıklarını, \%69.16'sı para ya da unvan kazanmadıklarını belirtmişlerdir. Para ve unvanın bir arada sorulmasının sebebi, kitle 
katılımlarında sosyal medya, üre-tüketicilerine maddiyattan çok kimlik inşasında değer kazandırdığını vurgulamak adınadır.

Ankette kullanılan dört sosyal medya platformunun ara yüzünün Türkçe olup olmamasının önemi katılımcılara sorulduğunda, katılımcıların \%10o’ü İngilizceye hâkim olmalarına rağmen, \%70’i sosyal medya platformunun ara yüzünün Türkçe olması gerektiğini vurgularken, ancak \%30’u İngilizce de olabileceğini belirtmiştir. Böylelikle sosyal medya platformlarının anadilde kullanımının diğer dillere göre daha çok tercih edildiği saptanmıştır. İngilizce gibi popüler ve hemen hemen her kelimesinin İngilizce terimlerle dolu olmasına rağmen, anadilde kullanımının daha kolay olduğu tespit edilmiştir. Her ne kadar popüler kültürün ortak dili İngilizce olarak belirlenmiş olsa da kullanıcıların çoğunluğu kendi dilinde olan sosyal medya platformlarını kullanmayı tercih etmektedirler. Dahası anadilde olan bir platformda alışveriş yapmanın daha kolay olup olmadığı sorulduğunda, katılımcıların \%71.66'sı ana dilde daha kolay olduğunu, \%26.66'sı daha kolay olduğunu düşünmediklerini, \%1.66'sı ise konuyla alakalı kararsız kaldıklarını söylemişlerdir. Ayrıca katılımcılara sosyal medya platformlarında anadillerinde içerik üretmek ve tüketmenin daha kolay olup olmadığı sorulduğunda, diğer cevapları onaylar şekilde \% 70’i daha kolay olduğunu, \%27.5’i daha kolay olduğunu düşünmediklerini, \% 2.5’i da kararsız kaldıklarını belirtmişlerdir.

Katılımcılara sosyal medya platformlarının popülere ve tüketim alışkanlıklarına etkisi sorulmuştur. Alışveriş seçimlerini sosyal medya platformlarına göre düzenleyip düzenlemedikleri sorulduğunda ise, katılımcıların \%80’i sosyal medyaya göre düzenlediklerini, \%17.5’i düzenlemediğini, \%2.5’i ise konu hakkında kararsız kaldığını beyan etmiştir. Dahası ankete katılan kişilerin \%87.5’i popüleri sosyal medyanın belirlediğini, \%9.16’sı belirlemediğini, \%3.3’ü ise kararsız kaldığını bildirmiştir.

Katılımcılara Google Çeviri Motoru gibi bilgisayar tabanlı çevrimiçi çeviri araçlarının ilerde çevirmenlik mesleğini ellerinden alacağını düşünüp düşünmedikleri sorulduğunda, \%56.6'sı çeviri motorlarının mesleklerini bitireceklerini, \% 34.16'sı ise mesleklerinin bu konuda tehdit altında olmadığını, \% 9.16'sı ise konu hakkında kararsızlıklarını belirtmişlerdir. Aynı soru kitle çeviri açısından sorulduğunda, katılımcıların \% 29.16'sı kitle çevirmenliğinin profesyonel çevirmenlik mesleğine zarar vereceğini, \%64.16'sı ise zarar vermeyeceğini belirtmiştir. \%6.66'sı ise kararsız kalmışlardır. Kitle çevirmenliği ile çeviri motorları arasındaki mesleğe zarar verme korkusu karşılaştırıldığında, katılımcıların çeviri motorları için daha endişeli oldukları izlenmektedir.

\section{Sonuç ve tartışma}

Küreselleşen dünyada Sosyal Medya Platformları dijital iletişim formatıyla dünyada çığır açmıştır. Zaman ve mekânla sınırlandırılmadan, enformasyonun hızlı ve anında dağılımı yeni medya platformlarını vazgeçilmez kılmış ve geleneksel medyanın önüne geçmiştir. Facebook, Google, Twitter gibi büyük sosyal medya platformları katılımcılarının ihtiyaçlarını ortak paydada toplarken, yeni ihtiyaçlar silsilesi oluşturmuş böylelikle eğlence, eğitim, sağlık, bakım, iletişim, haberleşme, teknoloji sektörünü elinde tutmuştur ve tutmaya da devam edecektir. Bu yeni ihtiyaçlarla oluşan yeni dijital kültür, evrenseldir. Kendine has kültürü, dili, iletişimi, yargısı, mahremiyeti, hukuku, etik kuralları bulunmaktadır. Gücünü katılımcılarından alan bu platformların temeli, ortaklık, sosyallik üzerine kurulduğundan yeni bir demokrasiye, dijital kamusal alan hukukuna ihtiyaç duymaktadır. Sosyal medya üzerine yapılan pek çok tartışma, katılımcıların artı değerlerini koruma adınadır. 
Hem üreten hem tüketen, hem etken hem edilgen olan katılımcıların en önemli özelliği gönüllük esasına dayanmasıdır. Katılımcıların $\mathrm{ml}$ sosyal medyayı, sosyal medyanın mı katılımciları yönlendirdiği tam olarak bilinmese de, sömürgeci devletlerin sömürgeleştirdikleri topluluklarla içkinleştiği gibi, her iki tarafın da birbiriyle etkileşim halinde olduğu apaçık ortadadır. Katılımcılık, sosyal medya platformlarının doğası gereği olması gerekendir. Müzikten, hikâye paylaşımına, "mention"dan "challenge" (meydan okuma) özelliğine, eğitimden oyunlara her şey katılım odaklıdır, katılım amaçlıdır.

Ana akım medyada popüler olan nasıl çoğunluğun beğenisine göre şekilleniyor ise, yeni medya platformlarında da kitle katılımı popüleri, böylelikle neyin tüketileceğini belirler. Özellikle içinde bulunduğumuz pandemi döneminde, sosyal medya, katılımcılarına, farkındalık oluşturmak için "evde kal" hashtagleri, çerçeveleri ve etiketleri hazırlamıştır. Kar amacı gütmeyen kişiler ve kuruluşlara kolay ve kısa sürede bağış yapabilme, çevrimiçi eğitim verebilme, görüntülü konuşma, ünlüler ve arkadaşları ile buluşma sağlayan çoklu görüşme platformlarına ücretsiz ulaşabilme, kısa sürede, kolay, çevrimiçi ve temassız alışveriş yapabilme gibi büyük önem arz eden imkânlar sağlamıştır. Bu sebeple pandemi döneminin de kalbinde atar hale gelmiştir. Zaten sürekli bağlı kalınan bu platformlara artık bağımlı olunmuştur.

Anket sonucuna göre, 120 kişilik anket katılımcısının 70’i sosyal medya platformlarında altı saatten fazla vakit geçirmektedirler, 41’i de dört-altı saat aralığında vakit geçirmektedir. Yani 120 kullanıcıdan 111'i, yani \%92.5’i en az dört saat bir gününü sosyal medya platformlarına vermektedir. Bu çok yüksek bir yüzde olup, sosyal medya platformlarında sadece popüleri ya da tüketici alışkanlıkların değil, dilin, kültürün, duygulanımların yani insana dair her şeyin yeniden şekillendiği izlenmektedir. Bu sebeple, sosyal medya platformları artık sadece boş zamanın geçirildiği, eğlenmek için zaman tüketilen mecralar olmaktan çıkmıştır.

Sosyal medya platformlarındaki kitle kaynak kullanımı gücü de yadsınamayacak kadar önemlidir. Bu çalışmada kitle gücünün çeviri sürecine etkisi de konu bağlamında tartışılmıştır. İnternete kolay erişim ve kısa sürede çok işin kotarılması sosyal medya platformlarında yenilikçi yansımalar yaratmıştır. "Kitle kaynak kullanımı" kavramı Türkiye'de de hızla büyüyen bir sektör yelpazesine yayılmakta olup ve uzun vadede kalıcı ve sürdürülebilir çeviri faaliyetlerinin önemli bir değeri olarak yerini almaya başlamıştır. Çoğunluğu topluluk haline getirerek topluluk adına seçimler yapmaya, yeni ürünler yaratmaya, aidiyet yaratmaya, bilgi üretmeye sevk etmektedir. Bu da tıpkı küresel dünyanın oluşumu gibi, iş yerlerinin dijitalleşmesini, çağa uygun yeni sektörler ve iş olanakları sağlamaktadır. Bu değişim bireyselden genele bir harekettir.

Kitle kaynak kullanımı, sosyal medyanın bir uzantısı olarak, "tüketicilerin" yani "katılımcıların" profilini kökten bir dönüşüme sokmuştur. Onları, sevdikleri ürünlerin geliştirilmesine veya inandıkları fikirlerin ilerlemesine katkıda bulunabilecek ve asıl ödülünü tam da bu bir topluluğa aidiyet duygusunda ve katkılarını sağlamada bulabilen bir topluluğun aktif üyeleri haline getirmiştir. Para artık katılımcılar için tek başına bir itici güç olmaktan çıkmış, yerini bu platformlardaki aidiyete ve değere bırakmıştır. Güçlü bir demokratikleştirme aracıdır. Amatör ruha şans tanıyarak, sektörü sadece profesyonelle değerlendirmeyerek yenilikçi, profesyonel ile amatörün beraber çalıştı̆̆ı, ürettiği, bilgilerini paylaştığı mekân ve zamandan muaf bir ortama imkân sunar. Amatör profesyonelden işin inceliklerini, profesyonel de amatörden yenilikçi ve farklı bakış açısı edinir. Böylece, gerçek iş dünyasında sanal dışında ulaşılamayacak bir potansiyele erişilir. Emeğin şekli dijitale evrilir. 
$\mathrm{Bu}$ evrim, çevirmenlik mesleğinin algılanma biçimini ve hatta gelecekte uygulanma biçimini etkileyen köklü değişikliklere de katkıda bulunur. Kitle kaynak kullanımı amatör ile profesyonel, çalışma ve boş zaman arasındaki sınırları bulanıklaştırırken, giderek daha güçlü ve iyi performans gösteren teknolojik araçlar, bilgisayar tabanlı çeviri araçları geliştirilmektedir. Tüm bu değişiklikler, çevirmenlik mesleğini tehlikeye atacağı düşünüldüğünden çoğu zaman ötelenir. Diğer yandan, teknolojik gelişimlerin hızlı gelişimi ile genel olarak çeviri ve dil hizmetlerine olan talep artarak devam etmektedir ve mevcut kaynaklar buna yetişememektedir. Bu yeni araçlar, yeni dijital kültüre bağlı değişiklikler ve gelişmelerle birlikte çevirmenlerin kullanacakları ve sektörün ihtiyacını karşılayacak geçerli seçenek olarak görülmektedir. Teknolojik gelişmeler çevirmenlik mesleğini sekteye uğratmaktan çok, çevirilerin tasarlanma ve gerçekleştirilme biçiminde geniş kapsamlı uyarlamalarla ancak çevirmenlere yardımcı olacaktır.

Kitle çevirisinin en çok kullanılan biçimi, yeni medyada dizi filmlerin dünya çapında en son sezonlarının daha hızlı yayılabilmesi için yapılan işbirliğine dayalı altyazı çevirileridir. $\mathrm{Bu}$, tamamen işbirliğine dayalı bir çalışma örneğidir. Çok kısa zamanda hızlı bir şekilde istenilen dillerin çevirilerine hayran kitleleri tarafından ulaşlan kaynak metinlerle, hayran kitlenin dizi film ile alakalı geçmiş bilgisi ve çeviri bilgisi ile birleştirildiğinde çevirideki kültürel ve metinsel aktarım kaynak metne daha sadık ve anlaşlabilir olmaktadır. Böylece üre-tüketici pozisyonundaki katılımcı hem sevdiği bir içeriğe katkıda bulunmuş, hem mesleğini icra etmiş, hem de emeğinin karşılığını çabucak bir geri dönüt olarak görmüş olmaktadır. Sosyal medya çevirileri de aynı şekilde işlemektedir. Hem bu platformlara hayran olan kitleyi hem de çevirmen kimliklerini birleştirip kültürel öğelerle harmanlandığında ortaya bütün bir sosyal medya platformunun ara yüzü çıkmaktadır.

Kitle kaynak uygulamaları ayrıca çeviriyi sadece ana amaç olarak değil, önemli bir araç olarak da kullanmaktadır. Örneğin herhangi bir Google motor çevirisinin yanlış olduğu düşünülen durumlar için kullanıcıların düzenleme yapabileceği bir düzeltme butonu bulunmaktadır. Böylelikle bilgisayar tabanlı bir çevirinin düzenlemesi, yerelleştirilmesi yine kitle çevirmenlerinin rolü ile gerçekleştirilir. Forum üzerinden diğer kitle çevirmenleri ile tartışılan belirli kelimeler, cümleler ya da ifadeler doğru şeklini alana kadar çevirmenlerin süzgecinden geçmiş olur. Aynı şekilde kitle katılımıyla yeni yeni kullanılmaya başlayan, daha çok yurt dışı menşeili ücretsiz çevrimiçi dil kurslarının, sözlüklerin ve yeni dijital sektörel çalışmaların, özellikle sosyal medyada ana dil kullanımı ihtiyacından, çevirilere ve kültürel aktarımlara ne kadar ihtiyaç olduğunu gösterir. Bu yeni ihtiyaç silsileleri ile birlikte sosyal medya platform katılımcılarının da görüşleri, algıları değişime uğrayacaktır. Pek çok sektör alışılagelmişin dışına çıkacağı gibi diğer mesleklerin kendilerini teknolojik gelişmelere göre şekillendirdiği gibi çevirmenlik mesleği de bununla birlikte kaçınılmaz bir dönüşüme geçecektir. Yeni medyanın değişim süreci devamlılık arz eder. Bundan güç alır ve sürekliliğini teknolojik gelişimlerin istikrarlı çıkışılla sürdürür.

Tüm yönleriyle derin bir etkiye sahip olan sosyal medya platformlarının, çeviri alanındaki kitle kaynak katılımıyla yürütülen projelerin başarılarıyla ve bu faaliyetlerin katılımcılar arasında artan ilgisine tanıklık etmekteyiz. Çeviri çoğu zaman "görünmez" bir faaliyettir. Fakat bu kitle katılım faaliyetleri ile geleneksele nazaran farklı bir çeviri algısı gelişmektedir. Çok daha geniş ve popüler bir kitleye hitap eden bu projeler, çeviri ve çok dilliliğin önemi hakkında farkındalık yaratmaya yardımcı olacaktır; düşünülenin aksine çevirinin statüsünü yükselecektir.

Sosyal medya pek çok araştırmada görüldü̆g̈u gibi popüleri elinde tutan, çeşitli kitlelerin tek bir yerden çıan sesi olan, farklı kültür ve dillerden ortak payda yaratabilen güce sahip önemli platformlardır. 
Kitle katılımı projeleri, katılımcı kültürün gönüllülük esası ve aidiyet hissiyatına dokunarak, katılımcıları için yeni çalışma alanları yaratmaktadır. Kitle çevirisi ile yaratılan çeviriler sadece sektörel yönden değil kültürel ve tüketim yönünden de öncelikle katılımcılarını sonra da toplumları etkilemektedir. Çeviri metinleri sayesinde kısa sürede dünyanın pek çok topluluğuna sosyal medya aracılığı ile ulaşılmakta ve böylelikle bu topluluklara veri dağılımı ve buna bağlı olarak farkındalık artmaktadır. Bu yönüyle de popüleri tüm dünya ülkelerine daha hızlı şekilde yaymak gibi bir misyonu da oluşmaktadır. Popülere bağlı olarak da katılımcıların ihtiyaçları ve tüketim alışkanlıkları bu platformlara göre şekillenmektedir.

\section{Kaynakça}

Alkan-Canım, S. (2017). Bulut tabanlı bir çeviri yönetim sisteminin çevirmenler açısından avantaj ve dezavantajları üzerine bir değerlendirme. Electronic Turkish Studies. 12(23), $69-88$.

Brown, R. (2009). Public Relations and Social Web. Kogan Page, London\&Philadelphia.

Bruns. Axel.(2008).Blogs, Wikipedia, Second Life, and beyond:From production to produsage. NewYork: Peter Lang.

Castells, Manuel. (2009). Communication Power. Oxford: Oxford University Press. 421.

Chomsky, Noam. (2002). Dil ve Zihin, Çev. Ahmet Kocaman, (İkinci Baskı), Ayraç, Ankara, 136.

Couldry, Nick. (2002).The Place of Media Power. London:Routledge.

Eco, Umberto. (2001). Açık Yapıt: Deneme. Çev. Pınar Savaş. İstanbul Can Yayınları.

Fuchs, Christian. (2015). Dijital Emek ve Karl Marx. Çev. Tahir Emre Kalaycı, Senem Oğuz. 1. Baskı Ankara: Notabene Yayınları.

Fuchs, Christian. (2016). Sosyal Medya Eleştirel bir Giriş. Çev. Diyar Saraçoğlu, İlker Kalaycı. 1. Baskı. Ankara: NotaBene Yayınları. Renas Yayıncılık. 113. 83.

Howe, Jeff. (2008). Crowdsourcing, Why the power of the crowd is driving the future of business. New York: Crown Publishing Group.

Henk van Ess. Crowdsourcing: How to find a crowd (Presented at ARD/ZDF Academy in Germany on 17 September 2010) http://www.slideshare.net/searchbistro/harvesting-knowledge-how-tocrowdsource-in-2010. 3

Jenkins,Henry.(1992). Textual poachers:Television fans and participatory culture. NewYork:Routledge. 25.

Kittur A., Chi E., Pendleton B., Suh B., Mytkowiczk T. (2006). Power of the Few vs. Wisdom of the Crowd: Wikipedia and the Rise of the Bourgeoisie Retreived from https://www.researchgate.net/publication/200772541

Murthy,Dhiraj.(2013). Twitter: Social Communication in the Twitter Age. Cambridge:Polity Press. 10

Ritzer, G. (2015). Prosumer Capitalism. The Socilogical Quaterly. 56(3). 413-445.

Saussure, F. De. (1985) Genel Dilbilim Dersleri (Çeviren: Berke Vardar), Ankara: Birey ve Toplum

Surowiecki, James. (2004). The Wisdom of Crowds. London: Abacus, p. XIII.

Toffler, A. (2008). Üçüncü Dalga bir fütürist ekonomi analizi klasiği. Çev. S. Yeniçeri. İstanbul Koridor Yayıncllı.358.

Üründü, Halit, Mehmet Tahir Öncü. (2018). Çeviribilimin Paradigmaları IV-Çeviri Seçkisi. 1. Baskı . İstanbul: Hiperlink Yayınları. 187.

Van Dijck, Jose. (2013). The Culture of connectivity: A critical history of social media. Oxford:Oxford University Press.45.

Vise, David A. (2005). The Google Story. London: Macmillan.4. 